\title{
Resilient Welded Steel Moment Connections by Enhanced Beam Buckling Resistance
}

\author{
Machel L. Morrison*, and Tasnim Hassan \\ Department of Civil, Construction and Environmental Engineering \\ North Carolina State University, Raleigh, NC USA \\ SUMMARY
}

This study develops two (2) simple but effective techniques for enhancing buckling resistance of welded steel moment connections (WSMCs). The ANSI/AISC 358-10 prequalified connections satisfy the $4 \%$ interstory drift requirement, however experimental studies have shown that their strength degradation may initiate as early as 3\% drift. This strength degradation has been observed to be initiated by buckling of the beam web which is followed by buckling of the beam flange and twisting of the beam. Consequently, buildings with the prequalified connections may sustain significant buckling damages under severe earthquakes and it is questionable as to whether these connections are capable of resisting gravity loads or lateral loads from strong aftershocks following a severe earthquake. To improve upon these shortcomings, two (2) performance enhancing techniques are proposed and investigated through finite element analysis (FEA).The more promising of the two involves reinforcing the beam web in the expected plastic hinge with a web reinforcement plate. Finite element analysis demonstrated that this reinforcement enhances the beam buckling resistance of WSMCs and thereby significantly reduces the beam buckling damages even at 5\% interstory drift. The potential of this technique is analytically and experimentally demonstrated for the recently developed heat-treated beam section (HBS) WSMC. Test results confirm that the web reinforcement plate was effective in reducing local buckling damage and associated strength degradation, thereby improving the performance of HBS WSMCs. Areas for application and future development of the proposed techniques are identified. 
29 Keywords: Steel moment connection; seismic performance enhancement; beam plastic hinge;

30 heat-treated beam section; web reinforcement tendency for connections to experience strength degradation is of concern as this strength degradation can increase rotational demands from P-delta effects and adversely affect frame

\section{Introduction}

More than a decade of research activities after the Northridge and Kobe earthquakes has developed modified designs of welded steel moment connections (WSMCs) with improved ductility [1]. By eliminating premature weld or near weld failures the current moment connections prequalified for special and intermediate moment frames (SMF and IMF) by the ANSI/AISC 358-10 [2] have demonstrated, the ability to attain at least 4\% interstory drift while sustaining $80 \%$ of the nominal flexural strength $\left(\mathrm{M}_{\mathrm{p}}\right)$. However, the ANSI/AISC 314-10 Seismic Provisions [3] notes that while connection qualification emphasizes plastic rotation capacity, the stability. In reported studies [4-8], prequalified connections such as the welded unreinforced flange-welded web (WUF-W), reduced beam section (RBS), extended end plate (EEP), bolted flange plate $(\mathrm{BFP})$ and Kaiser bolted bracket $(\mathrm{KBB})$ experience severe strength loss due to beam buckling prior to the termination of loading. Due to this rapid strength loss frame stability may be jeopardized in a severe earthquake and it is questionable whether these connections are capable of resisting gravity loads or strong aftershocks following such an event.

The majority of research efforts on the seismic performance of WSMCs have focused on circumventing weld or near weld failures which limited the attainable plastic rotation of these connections during the Northridge Earthquake [1]. However some research has been conducted on local beam buckling failures and the associated strength loss during seismic loading [9-11, 13,

15-17]. The following is a brief review of the findings of research studies conducted to either 
55 improve understanding of the local buckling failure modes of beam to column moment

57 failures.

58 Yu et al. [9] collected experimental data on the local buckling modes that result in strength connections or to prescribe and evaluate techniques to improve the resistance of WSMCs to such loss in RBS connections. Selected results from their test of an all welded RBS connection with a W30x99 beam connected to a W14x176 column are shown in Fig. 1a, for details of the experimental setup, loading history, instrumentation etc. the reader is referred to the research report from the study [9]. In Fig. 1a, the envelope of the applied load and measured buckling amplitudes are shown to illustrate the progression of local beam buckling and its effect on connection strength loss. These results indicate that web local buckling (WLB) and lateral torsional buckling (LTB) are initiated early in the loading history (between 1 and 2\% drift in the RBS region). It is noted that in RBS connections, the beam flanges are trimmed to relocate plastic hinging of the beam away from the column face to the reduced section and as a result, the largest bending stresses in the beam web occur in the reduced section. In this region, the beam web experiences less rotational restraint along its vertical edge (adjacent to the column flange) and along its horizontal edge (adjacent to the beam flange).Therefore, although trimming of the beam flanges improves flange compactness at the center of the reduced section, it increases the susceptibility of the beam to WLB. Yu et al. [9] also evaluated the effect of a near fault loading history and additional lateral bracing near the reduced section on the response of RBS moment connections through full scale experiments. The study showed that additional lateral bracing near the RBS region did not delay the onset of strength degradation but did slow the rate of strength degradation. Finally, finite element analysis reported in this study showed that the axial 
77 restraining effects from the columns in a frame system can also reduce strength degradation rates

78 for RBS moment connections.

79 Uang and Fan $[10,11]$ examined the stability criteria for steel moment connections with 80 reduced beam sections through nonlinear regression based on the test results of 55 full-scale RBS 81 moment connections. In their study, connection resistance to buckling induced strength 82 degradation was quantified by

83 1. The plastic rotation capacity $\left(\theta_{p c}\right)$, defined as the total plastic rotation beyond which a 84 connection starts to degrade below $80 \%$ of the peak strength (Fig. 1b). Plastic rotation is 85 calculated by dividing the plastic component of the beam tip displacement by the distance 86 from the beam tip to the column centerline.

87 2. The strength degradation rate (SDR) defined as the ratio of connection resistance (bending moment) at 0.03 and 0.02 radians plastic rotation (Fig. 1b).

By studying the statistical influence of flange slenderness ratio $\left(b_{f} / 2 t_{f}\right)$, web slenderness ratio $\left(h / t_{w}\right)$, slenderness associated with LTB $\left(L_{b} / r_{y}\right)$, and yield strength $\left(F_{y}\right)$ on connection

92 plastic rotation capacity $\left(\theta_{p c}\right)$, the following equation was developed by Uang and Fan $[10,11]$

93 to describe the relationship between these parameters:

$$
\begin{aligned}
& \theta_{p c} \\
& =5.8\left(b_{f} / 2 t_{f}\right)^{1 / 8}\left(h / t_{w}\right)^{1 / 2}\left(F_{y e}\right)^{1 / 2}
\end{aligned}
$$

94 where $b_{f}$ is the beam flange width, $t_{f}$ is the beam flange thickness, $\mathrm{h}$ is the clear distance between beam flanges less the fillet radius for rolled shapes, $t_{w}$ is the beam web thickness, $L_{b}$ is 
96 the unbraced beam length, $r_{y}$ is the radius of gyration about the y-axis, and $F_{y e}$ is the expected

97 yield stress defined as:

$98 \quad F_{y e}=R_{y} F_{y}$

99 where $R_{y}$ is the ratio of expected yield stress to specified minimum yield stress.

100 Eq. 1 was developed using the unreduced section properties. This equation does not include

101 the LTB slenderness ratio $\left(L_{b} / r_{y}\right)$, as LTB was not found to have much effect on the plastic 102 rotation capacity of connections in the data set examined [10, 11]. Note the relatively stronger 103 influence of the web slenderness ratio $\left(h / t_{w}\right)$, as compared to flange slenderness ratio $\left(b_{f} / 2 t_{f}\right)$ 104 predicted by the equation. This strong influence of web slenderness ratio on plastic rotation 105 capacity was discussed in detail by Uang and Fan $[10,11]$ who recommended a web slenderness 106 limit of $1100 / \sqrt{F_{y}}$ to ensure that connections are capable of achieving at least 0.03 radians 107 plastic rotation. This limit was later adopted in the ANSI/AISC 314-02 Seismic Provisions [12].

108 The limiting surfaces for various plastic rotation capacities based on eqn. 1 assuming grade 10950 steel $F_{y}=345 \mathrm{MPa}$ and $R_{y}=1.1$ are plotted in Fig. 1d, while the corresponding limiting 110 surfaces assuming $F_{y}=223 \mathrm{MPa}$ and $R_{y}=1.1$ are plotted in Fig. 1e. (Fig .1e will be discussed 111 in more detail later). The limiting flange and web slenderness ratios for highly ductile members 112 given in the ANSI/AISC 314-10 Seismic Provisions are shown in vertical and horizontal dashed 113 lines in Fig. 1d. As shown in the figure, conformance with these limits results in a connection 114 capable of attaining a plastic rotation capacity of 0.03 radians for grade 50 steel. Assuming an 115 elastic connection rotation of 0.01 radians, connections that satisfy these slenderness ratio limits 116 should be capable of achieving 0.04 radians total rotation or $4 \%$ drift with no greater than $20 \%$ 117 strength loss which is the prequalification criteria for connection use in special moment frames 118 [3]. Uang and Fan $[10,11]$ also showed that the concrete slab reduces the rate of strength 
119 degradation due to beam buckling under positive bending but not under negative bending. 120 Therefore, additional bracing from the concrete slab cannot be relied upon to effectively mitigate 121 strength degradation due to local beam buckling under load reversals.

122 Okazaki et al. [13] combined finite element analysis (FEA) with the nonlinear regression 123 techniques used by Uang and Fan $[10,11]$ to study lateral torsional and local buckling of beams 124 subjected to cyclic loads. The results of their study showed there to be an interaction between 125 both flange and web slenderness parameters on the strength loss of moment connections due to 126 buckling. The study also found that the stability requirements of the AISC 341-05 Seismic 127 Provisions [14] were adequate to maintain $80 \%$ of the nominal beam plastic moment $\left(\mathrm{M}_{\mathrm{p}}\right)$ at a 128 story drift of 0.04 radians.

129 The afore described studies have mainly focused on improving the understanding of the local 130 buckling failure modes of beam to column moment connections during seismic loading, 131 however, some attempts have also been made to delay the onset and slow the rate of strength 132 degradation due to buckling by various reinforcing methods. Kim et al. [15] identified web local 133 buckling as a trigger for strength degradation in their cyclic tests of welded cover plate 134 connections. As a result, they tested one welded cover plate specimen in which two pairs of 135 horizontal stiffeners were welded to the beam web approximately one quarter of the beam depth 136 from the top and bottom flanges in the expected plastic hinge region. While this may seem in 137 concept to be a relatively simple and economical method to delay the onset of strength 138 degradation without significantly increasing the strength of the connection, test results showed 139 that the stiffeners did not delay the initiation of strength degradation. As a result, Kim et al. [15] 140 instead recommended reduction of web slenderness limits for beams designed for seismic use as 141 opposed to adding web stiffeners. 
Wang et al. [16] also used horizontal web stiffeners on all-welded (welded flange-welded web) built-up non compact beams to delay the onset of strength degradation due to buckling.

144 These stiffeners were shop welded to the beam web and column flange on both sides of the beam 145 web in the anticipated plastic hinge region. Improvement in delaying the onset of strength 146 degradation was obtained when two pairs of stiffeners located one third of the beam depth from 147 the top and bottom flanges were used in lieu of one stiffener attached at the beam centerline. 148 However, this method is not suitable for typical WSMC construction practice in the United 149 States where beams are usually field welded to columns with bolted shear tabs because the 150 bolted shear tabs obstruct the attachment of the horizontal stiffeners on one side of the beam 151 web.

Li et al. [17] evaluated the local buckling of moment connections with RBS beams 153 subjected to cyclic loading using FEA. The study showed that, similar to the findings of Yu et al. 154 [9] supplemental lateral bracing near the reduced beam section provided only a modest 155 improvement in local buckling resistance. Therefore, the use of vertical stiffeners attached to the 156 beam web and beam flanges in the reduced section was investigated as a local buckling 157 mitigation technique. This investigation revealed that the use of two or three stiffeners placed 158 equidistant from each other in the reduced section delayed the onset and slowed the rate of 159 strength degradation. However, it was also discovered that the maximum stress within reduced 160 section was increased by $25 \%$ due to the addition of the stiffeners. This was found to be the 161 result of stress concentrations that tend to accompany the attachment of transverse stiffeners. In 162 previous studies $[18,19]$ stress concentrations from the attachment of vertical stiffeners were 163 found to be the cause of premature fractures when placed in regions that experience large 164 inelastic strains. Hence, despite its attractive features (effective in reducing strength degradation 
165 due to buckling, while being relatively simple to fabricate and install) transverse stiffeners may 166 not be a feasible option.

167 In several of the afore-described studies [10, 11, 13, 15], WLB in the plastic hinge has been 168 observed to play a strong role in the initiation and progression of connection strength 169 degradation. This has been found to be the case especially when connections are designed for 170 beam plastic hinging (as opposed to panel zone shear distortion) to dominate the inelastic 171 behavior. This form of instability (WLB) is expected due to the deep beams (with slender webs) 172 tested in lab experiments and is more closely related to the geometry of the beam rather than the 173 connection method and details. This strong influence of WLB on strength degradation has also 174 been observed during testing of a recently developed WSMCs involving a novel concept called 175 heat-treated beam section (HBS) [20, 21]. The study presented in this article will examine local 176 buckling and the associated strength degradation mechanism observed during full scale testing of 177 HBS connections. From this analysis, two (2) strategies to enhance the buckling resistance of all178 welded HBS connections are proposed and studied numerically through finite element analysis 179 (FEA). The more promising strategy is experimentally validated through full scale simulated 180 seismic testing. The experimental results from testing of the prototype specimen are analyzed 181 and compared to experimental results of otherwise identical HBS connections to demonstrate the 182 enhanced performance obtained from the proposed technique. Details of the experimental study 183 are presented and areas for future development and application of the proposed techniques are 184 identified.

\section{2. Buckling of recently developed seismically resilient WSMCs}

The heat-treated beam section (HBS) WSMC has been recently developed and validated

187 in other studies [20,21], however, for convenience a brief description of the HBS concept and 
application is presented here. This brief description is followed by a presentation of experimental data from recently tested HBS WSMCs demonstrating HBS seismic performance and local buckling strength degradation mechanism.

In HBS connections, specific locations of the top and bottom beam flanges are heated to a temperature in the range of $1050-1100^{\circ} \mathrm{C}$ for 15 minutes followed by slow cooling [20]. The heat-treated areas are highlighted red in Fig. 2a which show the HBS applied to an all-welded connection. This heat treatment reduces the strength of A992 steel as shown in Fig. 2b. As a consequence of this strength reduction, plastic hinging of the beam takes place in the heat-treated beam section (HBS). In a similar manner to the RBS, this connection provides a ductile seismic fuse through weakening, but because the elastic modulus of the heat-treated steel is unchanged, a connection modified with such a technique does not sacrifice elastic stiffness as does the RBS [20]. Note that HBS geometric parameters "a" which corresponds to the distance from the face of the column flange to the beginning of the HBS and " $b$ " which corresponds to the length of the HBS (Fig. 2a) may be chosen similar to RBS parameters "a" and "b" [20].

The moment-rotation responses shown in Fig. 3a and Fig. 3b demonstrate the seismic performance of identical all-welded HBS connections (HBS 5 and HBS 7 respectively) which exceeds current AISC 341-10 seismic provision [3] requirements for use in SMFs. These global responses of HBS connections show wide hysteresis loops indicating good energy dissipation. Strength degradation due to excessive local web, flange and lateral torsional buckling initiated during the $2^{\text {nd }}$ cycle of loading at $4 \%$ drift and continued during later loading cycles (see Fig. $3 \mathrm{a}$ and 3b). Loading of HBS 5 was terminated after sustaining 2 loading cycles at $5 \%$ drift due to a fracture in the location of significant flange buckling (see Fig. 3c) while loading of HBS 7 was terminated due to significant strength loss resulting from beam buckling (see Fig. 3d). 
To demonstrate the progressive strength degradation mechanism of HBS WSMCs 3-

212 dimensional and 2 dimensional plots (Figs. 4 and 5) of displacement measurements from LED

213 sensors placed on the beam flange and web of HBS 5 [20] are presented. In Fig. 5, FE

214 simulations are compared to the experimental responses and will be discussed in more detail

215 later. From these plots, local buckling of the beam web within the HBS is clearly noticeable at

$2163 \%$ drift (Fig. 4c and Fig. 5a). This beam web buckling was also visually observed at this point

217 in the loading history. At this same point in the loading history, flange buckling was neither

218 observed visually nor detected by LED sensor displacement measurements (Fig. 5a) [20]. This

219 indicates that similar to the RBS connection tested by Yu et al. [9] (Fig. 1a), web buckling

220 precedes flange buckling in HBS connections with this geometric configuration. During the first

221 excursion to $4 \%$ drift, beam flange buckling became noticeable (Fig. 5b).As loading progressed,

222 beam flange and web buckling amplitudes continued to increase as shown in Fig. 4d, by 5\%

223 drift, severe twisting of the beam web is noticeable (Figs. 4e and 5c) as well as double curvature

224 from buckling during loading in the opposite direction (negative bending).

225 This buckling damage is similar to those observed in previously studied WSMCs like the

226 RBS and WUF-W [9, 4] and have also been observed in other connections modified with the

227 HBS [21]. In other words, the buckling damage discussed above for HBS beams is not induced

228 because of the softening of material from the heat treatment or by the connection method, but it

229 is a characteristic behavior of the wide flange cross section.

230 3. Proposed techniques for enhancing beam buckling resistance of WSMCs

231 Based on the observed influence of WLB on the initiation of the strength degradation mechanism

232 of HBS (and other WSMCs), two (2) techniques to improve the local buckling resilience of HBS

233 WSMCs under seismic loading are proposed and evaluated through FE analysis. The first 
234 involves the attachment of a steel plate to the beam web and column flange in the anticipated 235 plastic hinge region. This "web reinforcement" (shown in Fig. 6a) is designed to reduce the 236 slenderness of the beam web in the region of anticipated buckling and provide greater resistance 237 to flexural buckling and twisting. By combining the web reinforcement with the HBS, plastic 238 hinging of the beam still takes place away from the welded joint, however strength degradation is 239 delayed and the rate of strength loss is reduced. The combination of these two features (HBS and web reinforcement) creates a connection that is resilient to both local buckling and weld fatigue failures. This connection is referred to as HBS-WR in the forthcoming discussion. web in the plastic hinge is proposed. This reduction of the material strength simply involves 244 extending the HBS to the beam web as shown in Fig.6b. As a consequence, flexural (and shear) stresses are reduced in the beam web without making any adjustments to the geometry. Note that

246 the heat treatment does not reduce the plastic modulus of A992 steel (note the downward shift of 247 the stress-strain curve shown in Fig. $2 b^{1}$ ). Therefore with reduced bending stresses acting on the 248 beam web in the plastic hinge, and no deterioration of the material plastic modulus, less buckling 249 damage and strength degradation is likely as a result. the plastic hinge is made homogeneous with respect to material yield strength. Based on eqn. 1 252 and Figs. 1c and 1d, with all else being equal, a reduction of material yield strength as shown in 253 Fig. 2b may significantly improve the plastic rotation capacity of a beam. The proposed 254 connection involving the extension of the HBS to the beam web is referred to as HBS-W in the 255 forthcoming discussion.

\footnotetext{
${ }^{1}$ In fact the work hardening rate of A992 steel increases as a consequence of heat treatment. The yield strength is reduced by $38 \%$, but the tensile strength is reduced by $25 \%$.
} 
It is important to note that the primary goal of the proposed modifications is to delay the

257 onset and slow the rate of connection strength degradation due to local beam buckling and not

258 necessarily to increase the moment capacity of the beam. While strength increase may

259 accompany the primary objectives, a significant increase in connection strength is generally

260 unnecessary as the design of moment resisting frames tends to be governed by the serviceability

261 and not the strength limit state [22]. In addition, significant strength increase may require

262 additional strengthening of column in order to avoid violating strong-column-weak-beam

263 (SCWB) criteria and excessive panel zone shear distortions.

\subsection{Finite Element Modeling of Enhanced Connections}

Three dimensional nonlinear finite element models were developed for the proposed

266 connections using the commercial finite element analysis software ANSYS Mechanical ADPL

267 [23]. Geometric and material nonlinearities were incorporated in the finite element models. An

268 example of the finite element mesh and boundary conditions is shown in Fig. 7a and Fig. 7b.

269 Displacement boundary conditions were applied so as to simulate typical experiment support

270 conditions [20], therefore hinge supports were applied to the columns ends while roller supports

271 were applied to the beam flanges close to the loading point (to provide lateral bracing).

272 Displacements were applied to the beam tip in accordance with the standard ANSI/AISC 341-10

273 [3] loading protocol for SMF connections.

The beam, column, web reinforcement and continuity plates were modeled with 8 noded

275 solid hexahedral elements (SOLID185) with selective reduced integration scheme. Welding

276 attachment of the web reinforcement plate to the beam web and column flange was simulated by

277 prescribing multi-point displacement constraints between the nodes of the web reinforcement

278 plate, column flange and beam web as shown in Fig. 7b. This method has been used in previous 
279 studies [4] to simulate reinforcing fillet welds between the beam web and shear tab in WUF-W

280 connections. The weld pattern shown in Fig. $7 \mathrm{~b}$ is intended to simulate attachment of the web

281 reinforcement plate through slot welds on the interior portion of the plate and fillet welds around

282 the edges. The thickness of the web reinforcement plate and its weld attachment to the beam web

283 was decided through trial and error. It was found that for the W30 X148 beam section studied, a

284 plate thickness matching or slightly greater $(3.2 \mathrm{~mm}$ or $1 / 8 \mathrm{inch})$ than the beam web thickness

285 produced optimal results. The web reinforcement plate is intended to be shop welded to the beam

286 web and then field welded to the shear tab.

287 Finite element models accounted for material nonlinearity through rate-independent

288 metal plasticity theory based on additive strain decomposition, the Von Mises yield criterion,

289 associated flow rule and Chaboche non-linear kinematic hardening rule [24]. The distinctive

290 feature of the Chaboche model is the superposition of non-linear kinematic hardening rules

291 according to Eqns. 6 and 7. This allows for accurate simulation of hysteric loop shape over a

292 wide strain range. A brief description of the Chaboche [24] model is given below.

293 Additive decomposition of each strain increment into elastic and plastic parts is considered:

$294 d \varepsilon=d \varepsilon^{e}+d \varepsilon^{p}$

295 The elastic strain increment $\left(d \varepsilon^{e}\right)$ is calculated by the generalized Hooke's law. The Von-Mises

296 yield criterion is expressed as:

$297 f(\underline{\sigma}-\underline{\alpha})=\left[\frac{3}{2}(\underline{s}-\underline{a}) \cdot(\underline{s}-\underline{a})\right]^{\frac{1}{2}}=\sigma_{0}$ 
298 where $\underline{\sigma}$ is the stress tensor, $\underline{\alpha}$ is the current center of the yield surface in the total stress space,

$299 \underline{s}$ is the deviatoric stress tensor, $\underline{a}$ is the current yield surface center in the deviatoric space, and $300 \sigma_{0}$ is the radius of the yield surface.

301 The plastic strain increment $\left(d \varepsilon^{p}\right)$ is calculated using the associated flow rule:

$302 \quad d \underline{\varepsilon}^{p}=d \lambda \frac{\partial f}{\partial \underline{\sigma}}=\frac{3}{2} d p \frac{\underline{s}-\underline{a}}{\sigma_{0}}$

303 Where the $d \lambda$ is the plastic strain multiplier and $d p$ is the scalar plastic strain increment.

304 The superimposed kinematic hardening rule is given by:

$305 d \underline{a}=\sum_{i=1}^{n} d \underline{a}_{i}$

$306 \quad d \underline{a}_{i}=2 / 3 C_{i} d \underline{\varepsilon}^{p}-\gamma_{i} \underline{a}_{i} d p$

307 Each of the superposed kinematic hardening rules has a strain hardening term ( $1^{\text {st }}$ term in Eq. 7) 308 and a dynamic recovery term ( $2^{\text {nd }}$ term in Eq. 7). $C$ and $\gamma$ are material parameters obtained from 309 fitting a stable single amplitude stress-strain curve from a uniaxial cyclic material test as shown 310 in Fig. 7c for A992 steel.

Geometric nonlinearities were accounted for via a large deformation formulation. During

312 the development of these finite element models it was found that with the cyclic displacement 313 loading history applied to the beam-column connections, local buckling of the beam is predicted 314 without the introduction of any eccentricities either from initial geometric imperfections or small 315 lateral loads. This observation has also been made by Myers [25]. Despite the symmetry of the 316 mesh, boundary conditions and applied loads, small eccentricities accumulate during cyclic 
317 loading. These eccentricities provides perturbation for local buckling simulation and in some

318 cases produces results of reasonable accuracy. However, the same is not true of monotonic

319 simulations; in fact, a monotonic FE simulation of a beam to column moment connection with

320 symmetric geometry, boundary conditions and loads will highly over predict the connection

321 capacity and fail to accurately predict local buckling.

324 complex and difficult to measure and model. Cyclic simulations in which buckling is perturb by

325 accumulated eccentricities can be viewed as an upper bound solution and may in some instances

326 make un-conservative predictions. Therefore, in this study initial geometric imperfections were

327 imposed by first conducting an eigenvalue analysis of the perfect structure and then prescribing a 328 scaled value of the first eigenmode displacement field as the initial configuration of the structure.

329 The scaling was chosen to represent realistic values of W-shape "out of squareness" based on ASTM A6 [26] tolerances. Similar approaches have been used in other studies [27-28].

To validate the FE model, the moment-plastic rotation response of HBS 5 is simulated

332 and compared to the experiment in Fig. 7d. In addition, the simulation of the cross-section 333 displacements with progressive local web and flange buckling of HBS 5 at a section $406 \mathrm{~mm}$

334 from the column face is compared to the experimentally measured displacements in Fig. 5. The 335 calculated connection plastic rotation during each loading cycle as well as the peak moments 336 show good comparison with the experimental responses (Fig. 7d). In addition, the cross-section 337 displacement predictions (Fig. 5) show very good correlation with the measured values and 338 appear to accurately capture the initiation and progression of local buckling of HBS 5.

\subsection{Finite Element Analysis Results and Discussion}


In order to quantify and analyze the effectiveness of the proposed methods response

341 parameters used by Uang and Fan [10] namely, plastic rotation capacity $\left(\theta_{p c}\right)$ and strength

342 degradation rate (SDR) (which were introduced earlier) are adopted in this study with one minor

343 change. The SDR is redefined as the ratio of connection resistance (bending moment) at the

344 plastic rotation corresponding to the maximum strength $\theta_{p M_{n}}$ to the connection resistance

345 (bending moment) at 0.01 radian plastic rotation greater than $\theta_{p M_{n}}$, i.e. $\theta_{p M_{n}}+0.01$.

$S D R=\frac{M_{@ \theta_{P} M_{n}}}{M_{@ \theta_{P} M_{n}+0.01}}$

This definition attempts to quantify the rate of strength loss immediately following the

initiation of strength degradation regardless of the plastic rotation at which the onset of

strengthen degradation occurs. This redefinition of the SDR was deemed appropriate for this

study since in some cases connections may not experience strength loss between 0.02 and 0.03

radians plastic rotation as was assumed by Uang and Fan [10, 11]. Response parameters were

computed for both positive and negative bending and the average values are reported.

Proposed connections HBS-WR and HBS-W were subjected to cyclic loading prescribed

354 simulations the applied beam tip displacements were increased in accordance with the loading

355 protocol until the connection strength had degraded below $80 \%$ of its maximum value. The

356 moment-plastic rotation envelops for the proposed connections are compared to the earlier

357 presented HBS 5 and HBS 7 connection experimental and simulation responses in Fig. 8. It is

358 noted that while the geometry of HBS 5 and HBS 7 was identical, their material yield strengths

359 varied [20]. This accounts for the noticeable variation in their moment responses. The moment-

360 plastic rotation envelops in Fig. 8 were used to determine the plastic rotation capacities and

361 strength degradations rates tabulated in table 1. In addition, the accumulated equivalent plastic 
362 strain contour plots at 5\% story drift for HBS, HBS-W and HBS-WR simulations are presented

363 in Fig. 9. Note that in the simulations the beam and column sections, dimensions, boundary

364 conditions and loading history for HBS-WR and HBS-W connections are identical to that used

365 for the HBS connection. Analysis of table 1 and Figs. 8 and 9 have led to the observations

366 discussed in the following.

367 The addition of the web reinforcement plate increases post yield connection stiffness and 368 strength (see Fig. 8). It also delays the onset of buckling, increases the plastic rotation capacity 369 by $50 \%$, and gives a mild improvement in the strength degradation rate (see table 1). As a result, 370 energy dissipation is improved significantly and buckling damages are also reduced (compare 371 Fig. 9a and 9b with Fig. 9e and 9f).

372 As an alternative, extending heat-treatment to the beam web (HBS-W) reduces 373 connection strength (Fig. 8). Though it does not delay the onset of strength loss, it significantly 374 reduces the rate of degradation (Fig. 8) and the associated local buckling damage in the plastic 375 hinge (compare Figs. 9a and 9b with Figs. 9c and 9d). As a result, extending heat-treatment to 376 the beam web improves the plastic rotation capacity by $40 \%$ and also contributes to a significant 377 improvement in the SDR (see table 1).

In addition to improving buckling resilience, the proposed strategies are also fatigue

379 resilient as in both cases most of the yielding and damage takes place away from the welded joint 380 (see Fig. 9). Although being more involved from a fabrication standpoint, beam web 381 reinforcement (HBS-WR) does seem to provide greater improvements in seismic performance.

382 Based on these results, full scale testing was conducted to validate the web reinforcement 383 technique as described in the following.

\section{4. Experimental Validation}


One large scale exterior moment frame sub-assemblage specimen (HBS 8) was tested to

evaluate the performance enhancement provided by the web reinforcement. The test setup and details of the test specimen are shown in Fig. 10. The beam and column section sizes, lengths, and support conditions were chosen to be identical to those of HBS 5 and HBS 7. In addition, the welding details for the attachment of the beam flange and beam web to the column flange (shown in Fig. 10b) remained identical to those of HBS 5 and 7. This allowed for direct comparisons to be made between the performance of otherwise identical connections with and without web reinforcement.

The web reinforcement plate was fabricated in the shop with horizontal and vertical slots as shown in Figs. 10b and 10d. Shop welding of the web reinforcement plate to the beam web was accomplished using gas shielded metal arc welding (GMAW) with E71T-1C-H8 electrodes which is specified to meet the requirements of AWS D1.8. Fillet welds were used to connect the perimeter of web reinforcement plate to the beam web and were also placed in the vertical and horizontal slots to provide added reinforcement to the beam web. This design (length and pattern of welds) was determined using the FE modeling presented earlier (see section 3).

Upon completion of beam fabrication, heat treatment was performed using electrical resistance ceramic mat heating pads as shown in Fig.11a. Heating pads were sized according to the required dimensions of the HBS and were installed on the inner and outer surface of the beam flanges. The heating pads were connected to a power supply and type $\mathrm{K}$ thermocouples were used to monitor temperatures and provide continuous feed back to the power supply. Three (3) layers of $50 \mathrm{~mm}$ (2 in.) high density ceramic fiber insulation blankets were wrapped around the beam flanges as shown in Fig. 11b to provide well controlled heating and cooling. More details about the heat treatment setup and procedure are provided in [20, 29]. 

to actual field conditions) by a welder qualified in accordance with the requirements of AWS D1.1-10 and AWS D1.8-09. Welding was accomplished with self-shielded flux cored arc

411 welding (FCAW) process. E70-T6 electrodes were used for beam flange complete joint

412 penetration (CJP) welds which were made in the down hand position, while E71-T8 electrodes

413 were used for the beam web CJP weld and reinforcing fillet welds which were made in the 414 vertical and overhead positions respectively. Both of these electrodes were specified by the 415 manufacturer to deposit metal with a minimum Charpy V-notch toughness of $27 \mathrm{~J}(20 \mathrm{ft} .-1 \mathrm{bs}$.) at $416-28^{\circ} \mathrm{C}\left(-20^{\circ} \mathrm{F}\right)$. The bottom flange backing bar was removed and a reinforcing weld was placed

417 at the root of the grove weld. The top flange backing bar was left in place, however a fillet weld 418 was provided between the backing bar and the column flange. Weld tabs from the top and 419 bottom beam flange CJP welds were removed by carbon air arc gouging. After the beam to 420 column CJP welds were completed, a CJP weld was installed between the shear tab and the web 421 reinforcement plate as shown in Fig. 10b. Finally, all CJP welds were ultrasonically (UT) tested 422 by a certified welding inspector (CWI) in conformance with AWS D1.1-10 and AWS D1.8-09. 423 More details on the welding procedures, specifications and parameters are provided in [29]. Each specimen was equipped with strain gauges along the beam flanges to monitor 425 longitudinal flange strains at various locations including the weld toe and HBS region. String and 426 linear potentiometers were used to monitor displacements and rotations in the beam, column, and 427 panel zone. A calibrated load cell in the hydraulic actuator provided readings of force response 428 during the experiment. The specimen was also painted with hydrated lime prior to testing to 429 visually indicate regions of yielding. 
The Optotrak Certus HD three-dimensional (3D) position system was used to capture the

431 positions of markers placed along the beam flanges and web (Fig. 3). Position time history data

432 obtained from this system was post processed to calculate displacements and strains in areas of

433 interest.

434

435

436

437 5. Test Results

438 5.1. Global response of $\mathrm{HBS} 8$

439

Testing was conducted at the North Carolina State University Constructed Facilities

440 Laboratory (CFL). Loads were applied at the beam tip in accordance with the 2010 ANSI/AISC

441 341-10 [3] loading protocol consisting of quasi-static increasing amplitude displacement cycles.

442 Fig.12a shows the moment-rotation response of HBS 8. This global response shows wide and 443 stable hysteresis loops. HBS 8 met the 2010 AISC Seismic Provisions (ANSI/AISC 341-10)

444 SMF qualifying 4\% interstory drift angle without strength loss. Slight strength degradation due

445 to a fracture sustained in the fillet weld of the vertical slot in the center of the web reinforcement

446 plate, was observed during the $1^{\text {st }}$ cycle of loading at 5\% story drift. Photographs of this fracture

447 are shown in Fig. 16 and will be discussed more later. Loading of HBS 8 was terminated after

448 completing 1 cycle at 5\% story drift as a result of this failure.

449 5.2. Comparative Analysis of $H B S 8$

$450 \quad$ 5.2.1 Global Response

451 The peak moment-plastic rotation response of HBS 8 is compared to those of HBS 5 and

452 HBS 7 in Fig. 14. As anticipated from pretest analysis, HBS 8 displays increased strength and 
453 stiffness compared to HBS 5 and HBS 7. The onset of strength degradation was also delayed in

454 HBS 8 which validates the concept of improving buckling resistance of wide flange beam to 455 column HBS moment connections through web reinforcement.

456

457

458

459

460

461

462

463

464

465

466

467 distributed beam flange flexural strains over the plastic hinge region. As a result, at comparable

468 drift angles, strain demands are lowered in the heat treated region in HBS 8. This effect leads to a

469 favorable condition both in terms of fatigue resistance and delay of beam flange local buckling.

\section{$470 \quad$ 5.2.3 Local buckling}

471

472 from the column flange of HBS 5 and HBS 8 at 3\%, 4\% and 5\% interstory drift. Dotted lines

473 have been traced between data points to make evident the progressive buckling of the beam. Fig.

47415 compares photographs of HBS 5 and HBS 8 at corresponding stages of the loading history. 
475 These two figures provide validation of the web reinforcement plate technique in significantly

476 reducing FLB, WLB and LTB for HBS beam to column moment connections. Note that even

477 though no reinforcement of the flanges was provided, flange local buckling is significantly

478 reduced by the presence of the web reinforcement plate (compare Figs. 15c and 15f). This

479 supports the findings of Uang and Fan [10, 11] and Okazaki et al. [13] who both demonstrated

480 the interaction between non dimensional web and flange slenderness parameters through

481 nonlinear regression analysis. Evidence from the experimental results presented in this article

482 suggests that WLB and FLB are at the least weakly coupled. Reduced flexural strains along the

483 beam flanges as demonstrated in Fig.13 may have been a contributing factor to the reduced local

484 flange buckling observed in HBS 8.

$485 \quad$ 5.2.4 HBS 8 Web reinforcement plate fillet weld failure

486 As previously stated loading of HBS 8 was terminated after one complete loading cycle at $5 \%$

487 story drift due to a crack in the bottom of the fillet weld in the vertical slot of the web

488 reinforcement plate. Photographs of the failure location and rupture are shown in Figs. 16a and

$48916 \mathrm{~b}$ respectively. The crack which measured $127 \mathrm{~mm}(5 \mathrm{in}$.$) in length propagated through the$

490 beam web and extended vertically as shown in Fig. 16b, resulting in strength loss as shown in

491 Fig. 12a. This failure underscores the well-established understanding that fillet welds are less

492 ductile when loaded perpendicular to their longitudinal axes. In addition, the "v-shaped"

493 topography of the fillet welds in the web reinforcement plate slots (Figs. 16b and 16c) create an

494 unfavorable stress concentration which may have also contributed to this failure.

\section{6. Future Work on proposed techniques}

496 Due to the limitation of resources, this study was conducted on a rolled wide flange section

497 with relatively compact web and flange elements. As demonstrated in the above review of the 
literature, some rolled wide flange beams do suffer from severe strength degradation due to buckling. However, many of these shapes satisfy the requirements for highly ductile members in the 2010 ANSI/AISC seismic provisions [3] and as a result are able to meet the 0.03 radians plastic rotation capacity required for use in SMFs (see Fig.1c). Therefore, the strategies outlined in this article are anticipated to add greater value in enhancing the buckling resistance of built-up I-shaped beams whose web and flange elements don't satisfy width-to-thickness ratios of highly ductile members according to the 2010 ANSI/AISC seismic provisions [3], thus limiting their applicability to intermediate or ordinary moment frames. For example, Figs. 1c, 1d and $2 \mathrm{~b}$ show that with the reduction of yield strength by the heat treatment, the plastic rotation capacity of a grade 50 steel beam that does not satisfy width-to-thickness ratios to be considered highly ductile [3] (i.e. a beam with $h / t_{w}$ ratio lying above the horizontal dashed line and/or a $b_{f} / 2 t_{f}$ ratio lying to the right of the vertical dashed line shown in Fig. 1d) can be significantly improved as shown in Fig. 1e. FE analysis of HBS-W supports this prediction. The web reinforcement plate also provided significant improvement to plastic rotation capacity and was experimentally validated. In addition, both of the proposed techniques also have the potential to be used as retrofit techniques for seismic upgrades.

The research conducted in this study falls far short of that needed for development of design details and equations, therefore, further studies are necessary to continue to develop and improve these methods. Future studies on the web reinforcement technique should incorporate more detailed FE analysis to optimize the reinforcement plate weld attachment design so as to minimize stress and strain concentrations, welding induced distortions and cost. It is recommended that vertical slots with fillet welds be avoided based on the results of the current study. In addition, experimental validation is required for the HBS-W technique. It is 
521 recommended that future numerical and experimental studies should include application of these

522 techniques to built-up I-shaped beams whose web and flange elements may only satisfy width to

523 thickness ratios to be considered moderately ductile according to the 2010 ANSI/AISC seismic

524 provisions [3].

525 Another attractive application of these techniques (particularly the web reinforcement

526 technique) may be their use at the column base plastic hinge location in moment frames which

527 employ deep columns (W27 and deeper sections). These deep members have reduced torsional

528 properties and more slender web and flange elements when compared to the W14 and shallower

529 sections traditionally used for columns in gravity frames. In addition, unlike beams, these

530 members carry compressive axial loads (from gravity forces) and are expected to sustain large

531 plastic rotations during the formation of a beam sway mechanism in a severe earthquake. Recent

532 experimental [30] and analytical research [31] on the behavior of deep columns (constructed

533 from rolled wide flange sections) in moment frames subjected to combined lateral and axial

534 loads have shown them to be susceptible to severe strength degradation at interstory drift levels

535 below the required 4\%. Web slenderness was found to play a significant role in this strength

536 degradation mechanism [31] and as such, it is anticipated that the techniques outlined in this

537 study may provide a viable solution to this problem.

\section{7. Conclusion}

Strength degradation initiated by local buckling damages in WSMC's have been studied

540 experimentally and through FE analysis. This strength degradation is observed to be initiated by

541 buckling of the beam web which is followed by buckling of the beam flange and lateral torsional

542 buckling in the plastic hinge. It is observed that once this strength degradation initiates it

543 propagates quickly with continued incremental cycles. By $4 \%$ interstory drift test data show that 
544 local beam web and flange buckling damages in the plastic hinge region become large. To 545 counter this, two techniques for improving the seismic performance of HBS WSMCs have been 546 proposed and studied through finite element analysis. One technique involves welding a 547 reinforcement plate to beam web and column flange in the plastic hinge region, while the other 548 technique involves extending the HBS to the beam web. FE studies show both techniques to be 549 fatigue resilient (i.e. plastic hinge forms away from welded joint) and to reduce local buckling 550 damage and associated strength degradation.

551 The web reinforcement technique was validated through full scale simulated seismic 552 testing. Test results show the web reinforcement to be effective in improving stiffness, reducing 553 buckling damages and delaying the onset of strength degradation of HBS WSMCs. Results show 554 that these benefits are obtained without changing the plastic hinge location. In fact, it was 555 observed that the addition of the web reinforcement plate results in more widely distributed (less 556 concentrated) flexural strains in the plastic hinge. However, test results also show that careful 557 detailing of the welding attachment of the reinforcement plate to the beam web is necessary to 558 circumvent unwanted failures to these welds.

559 Areas for application of these techniques such as seismic upgrades or new construction of 560 moment frames involving non-compact beams, and the reinforcement of column bases 561 constructed from deep wide flange sections have been identified. Suffice it to say that future 562 analytical and experimental studies are needed to further develop and eventually implement these 563 techniques in the field. In this regard, the experimental and analytical findings of the current 564 study should provide a valuable starting point for such efforts. 
566 Funding for this research was provided by the National Science Foundation under the Network

567 for Earthquake Engineering Simulation (NSF Grant no. 0936547). However, any opinions

568 presented in the paper are solely those of the authors. The authors greatly acknowledge the

569 efforts and assistance provided by the staff of Furmanite Inc., Steel Fab Inc., Flores Welding Inc.

570 and the Constructed Facilities Laboratory (CFL) at NCSU. In addition, the early efforts of

571 Shahriar Quayyum and Doug Schweizer are acknowledged.

572

\section{References}

573 [1] FEMA-355D, (2000). State of the Art Report on Connection Performance, prepared by the

574 SAC Joint Venture for the Federal Emergency Management Agency, Washington, DC.

575 [2] AISC/ANSI 358-10 (2010). Prequalified Connections for special and intermediate steel 576 moment frames for Seismic Applications, Chicago.

577 [3] AISC/ANSI 341-10 (2010). Seismic Provisions for structural steel buildings, Chicago.

578 [4] Ricles, J.M., Mao, C., Lu, L.W., \& Fisher, J.W. (2000). Development and Evaluation of

579 Improved Details for Ductile Welded Unreinforced Flange Connections. SAC Joint Venture:

580 Report SAC BD-00/24.

581 [5] Jones, S.L., Fry, G.T., and Engelhardt, M.D., (2002). "Experimental Evaluation of Cyclically

582 Loaded Reduced Beam Section Moment Connections.” J. Struct. Eng, Vol. 128, pp. 441-451.

583 [6] Sumner, E.A., and Murray, T.M. (2002). "Behavior of extended end-plate moment

584 connections subject to cyclic loading.” J. Struct. Eng, Vol. 128, No. 4 pp.501-508.

585 [7] Schneider, S.P. and Teeraprbwong, I. (2002). "Inelastic Behavior of Bolted Flange Plate

586 Connections.” J. Struct. Eng, Vol. 128, pp. 492-500. 
587 [8] Adan, S.M., \& Gibb, W. (2009). "Experimental evaluation of Kaiser Bolted Bracket steel 588 moment-resisting connections.” Engineering Journal, 181-195.

589 [9] Yu, Q. S. Yu, Gilton, C., Uang C.M. (2000). Cyclic Response of RBS Moment Connections:

590 Loading Sequence and Lateral Bracing Effects. SAC Joint Venture: Report SAC BD-00/22

591 [10] Uang C.M. and Fan C.C. (1999). Cyclic instability of steel moment connections with 592 reduced beam section. SAC Joint Venture: Report SAC BD-99/19.

593 [11] Uang, C. and Fan, C. (2001). "Cyclic Stability Criteria for Steel Moment Connections with 594 Reduced Beam Section.” J. Struct. Eng., 127(9), 1021-1027.

595 [12] AISC/ANSI 358-02 (2002). Seismic Provisions for structural steel buildings, Chicago.

596 [13] Okazaki, T., Liu, D., Nakashima, M., \& Engelhardt, M. D. (2006). "Stability requirements 597 for beams in seismic steel moment frames.” J. Struct. Eng, 132(9), 1334-1342.

598 [14] AISC/ANSI 358-05 (2005). Seismic Provisions for structural steel buildings, Chicago.

599 [15] Kim, T., Whittaker, A.S., Bertero, V.V., Gilani, A.S.J., and Takhirov, S.M. (2000). Steel 600 Moment Resisting Connections Reinforced with Cover and Flange Plates. SAC Joint Venture: 601 Report SAC BD-00/27.

602 [16] Wang, W., Zhang, Y., Chen, Y., \& Lu, Z. (2013). "Enhancement of ductility of steel 603 moment connections with noncompact beam web." Journal of Constructional Steel Research, $60481,114-123$.

605 [17] Li, F., Kanao, I.,Li, J., and Marisako, K. (2009). “Local Buckling of RBS Beams Subjected 606 to Cyclic Loading.” J. Struct. Eng., 135(12), 1491-1498. 
607 [18] Chao, S. H., Khandelwal, K., and El-Tawil, S. (2006). "Ductile web fracture initiation in 608 steel shear links.” J. Struct. Eng., 132(8), 1192-1200.

609 [19] Okazaki, T., Engelhardt, M. D., Nakashima, M., and Suita, K. (2006). “Experimental 610 performance of link-to-column connections in eccentrically braced frames.” J. Struct.

611 Eng., 132(8), 1201-1211.

612 [20] Morrison, M., Schweizer, D., and Hassan, T. "An innovative seismic performance 613 enhancement technique for steel building moment resisting connections." Journal of 614 Constructional Steel Research 109 (2015): 34-46.

615 [21] Morrison, M. L., Schweizer, D. Q., and Hassan, T. (2016). "Seismic Enhancement of 616 Welded Unreinforced Flange-Bolted Web Steel Moment Connections.” J. Struct. 617 Eng., 04016102.

618 [22] SEAOC (2013). 2012 IBC structural/seismic design manual, Vol. 4: Example for steel619 framed buildings, Structural Engineers Association of California, Sacramento, CA.

620 [23] ANSYS® Academic Research, Release 14.5, Help System, Structural Analysis Guide, 621 ANSYS, Inc.

622 [24] Chaboche, J. L. (1986). "Time-independent constitutive theories for cyclic plasticity." Int. 623 J. Plast., 2(2), 149-188.

624 [25] Myers A, (2009). "Testing and probabilistic simulation of ductile fracture initiation in 625 structural steel components and weldments" Ph.D. dissertation, Stanford University, Stanford, 626 CA 
627 628

629 Conshohocken, PA.

630 631 632 633

634 Research Center, Lehigh University, Bethlehem, PA.

635 [29] Schweizer, D.,Q., "Experimental Investigation of Innovative Seismic Performance 636 Enhancement Techniques for Steel Building Beam to Column Moment Connections”, (Thesis) 637 North Carolina State University, Raleigh, NC.

638 [30] Newell, J., and Uang, C. (2006). Cyclic behavior of steel columns with combined high axial 639 640 California, San Diego, La Jolla, CA.

641 [31] Fogarty, J. and El-Tawil, S. (2015). "Collapse Resistance of Steel Columns under Combined 642 Axial and Lateral Loading." J. Struct. Eng., 10.1061/ (ASCE)ST.1943-541X.0001350, 64304015091.

\section{Figures}


(a)
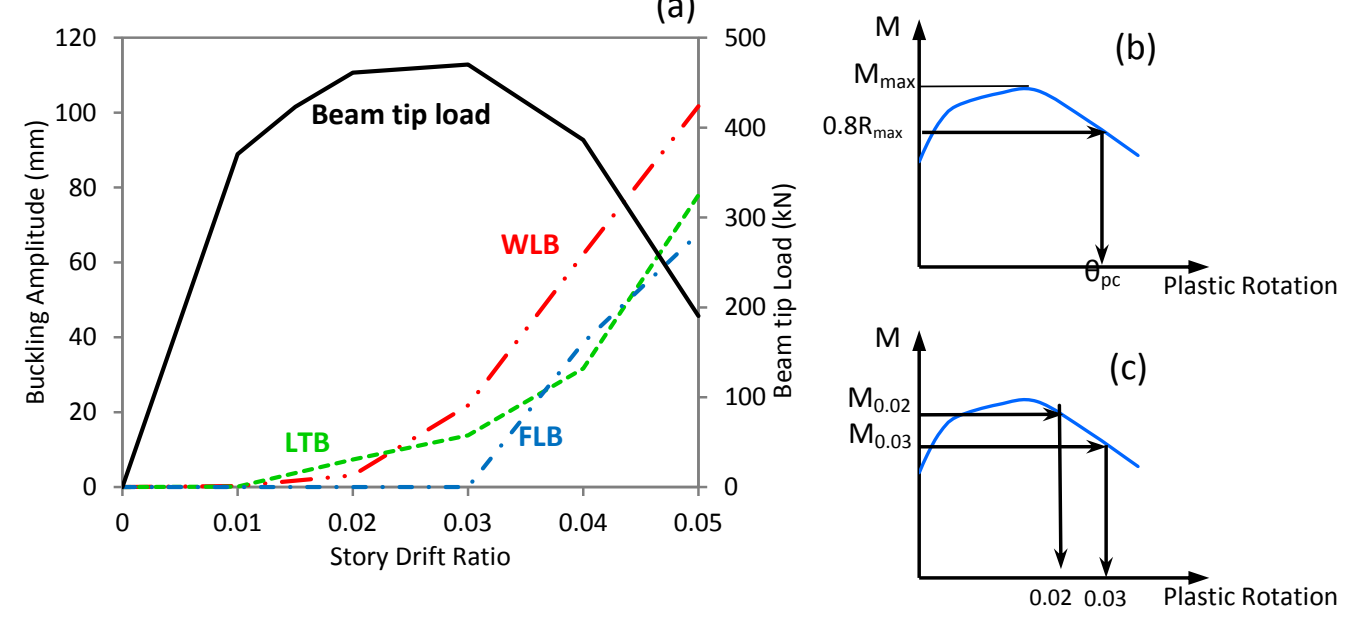

(d)
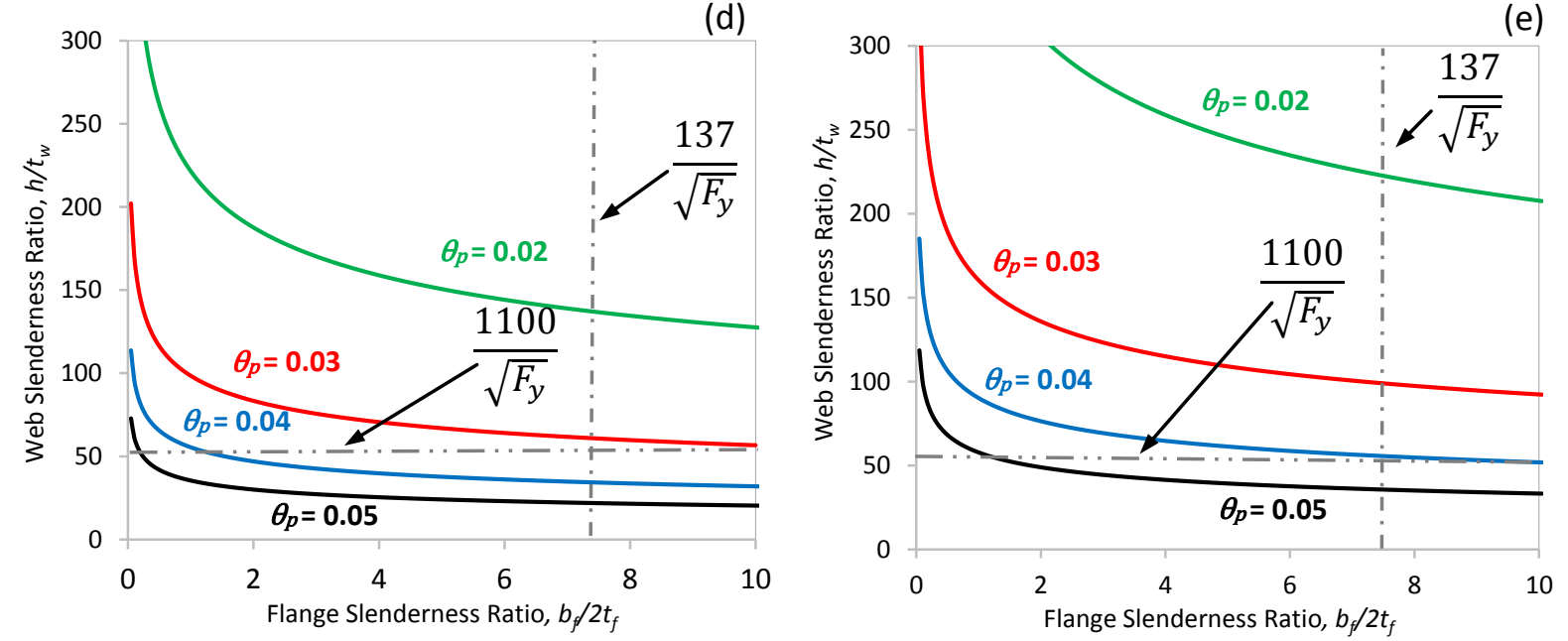

645 Fig. 1. (a) Measured local buckling modes and strength degradation of a RBS beam to column

646 moment connection (Data from Yu et. al [9]) (b) Definition of plastic rotation capacity by Uang

647 and Fan [10] (c) Definition of strength degradation ratio by Uang and Fan [10] (d) Limiting

648 Slenderness Surfaces for RBS beam to column moment connections $\left(F_{y}=345 \mathrm{MPa}\right)[10]$ (e)

649 Limiting Slenderness Surfaces for RBS beam to column moment connections $\left(F_{y}=223 \mathrm{MPa}\right)$

$650 \quad[10]$. 


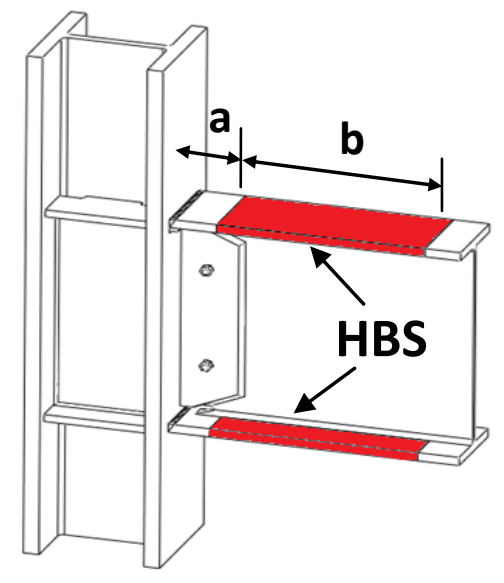

(a)

(b)

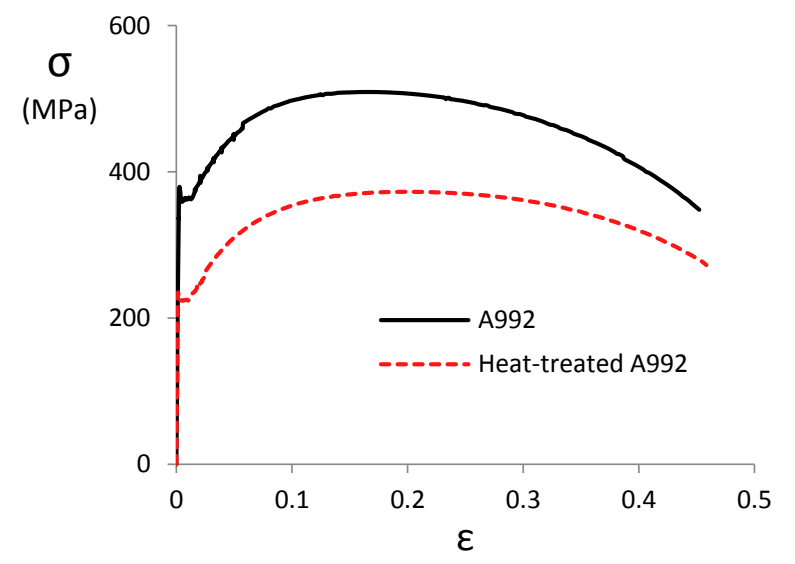

Fig. 2. (a) Sketch of heat-treated beam section (HBS) connection [20] (b) engineering stress-strain response of A992 and heat-treated A992 steel [20]
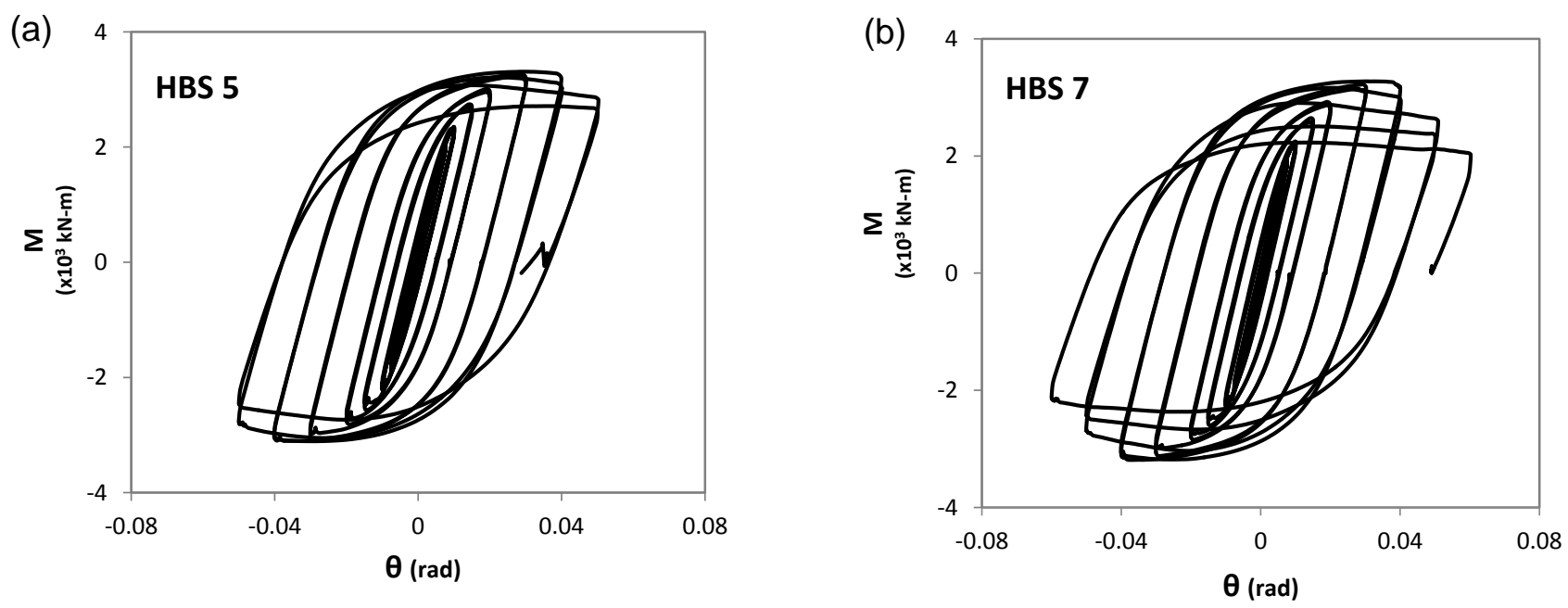


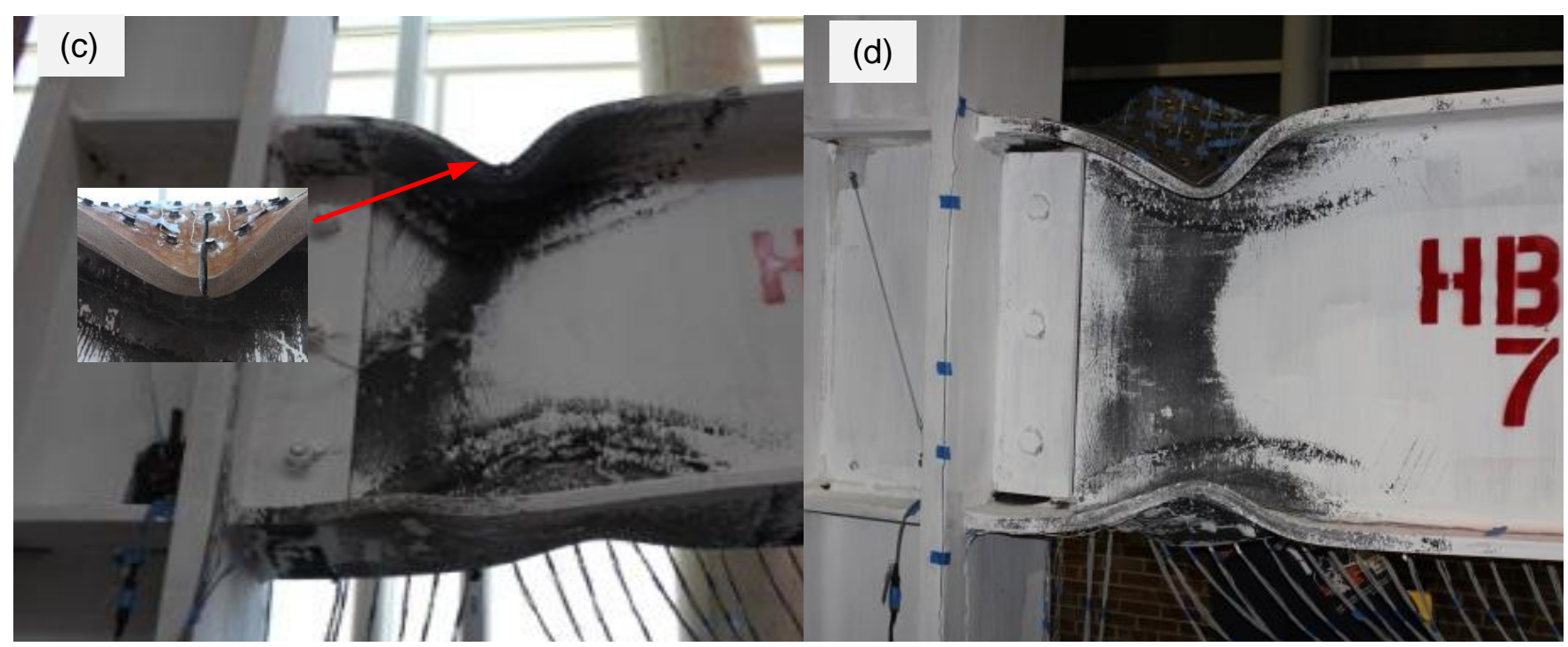

Fig. 3. Test results of HBS 5 and HBS 7 WSMCs, (a) HBS 5 moment-rotation response [20] (b) HBS 7 moment-rotation response [20] (c) photograph showing HBS 5 beam flange buckling and fracture at the crest of flange buckle (d) photograph showing plastic hinge formation and significant beam flange buckling of HBS 7 .
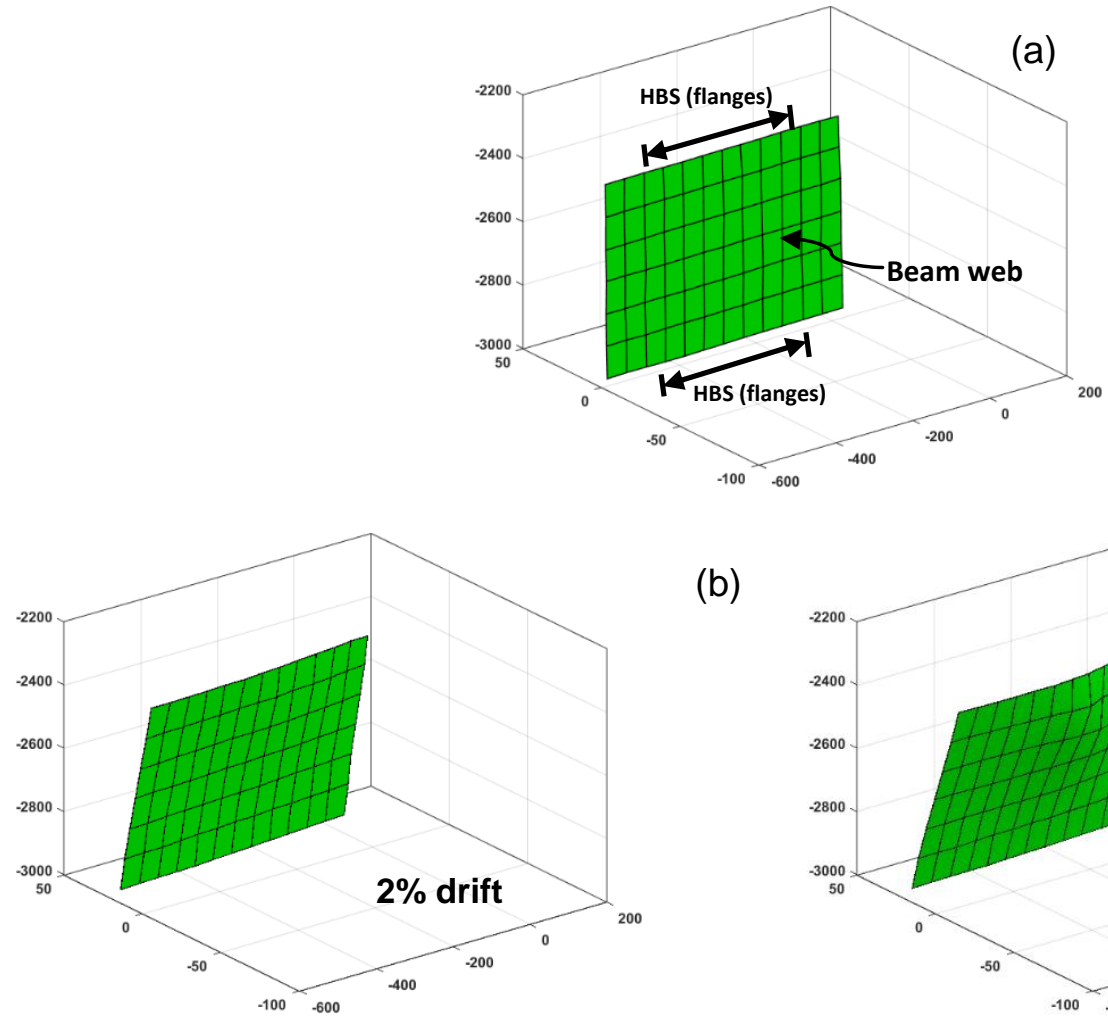

(b)



(c) 


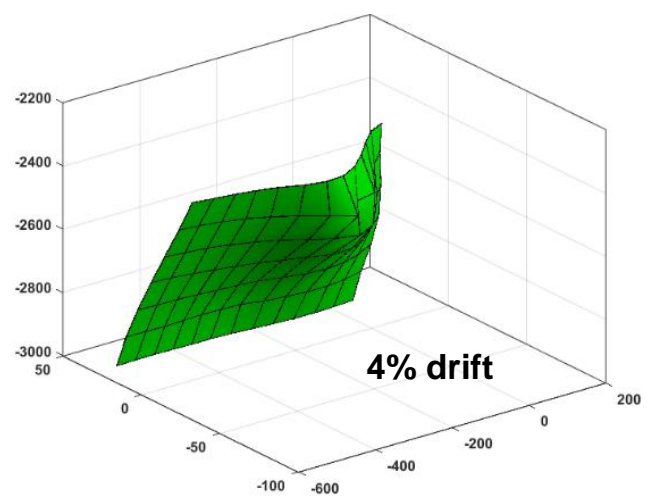

(d)

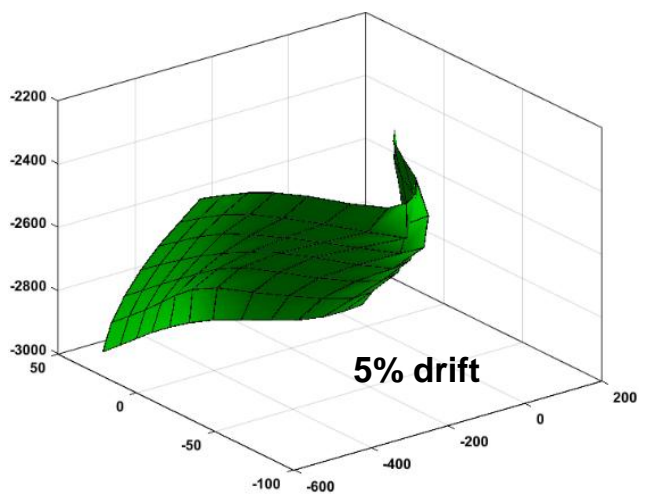

(e)

Fig. 4. Progression of buckling in beam web of HBS 5 at various stages of loading history (a) initial position (b) $2.0 \%$ drift (c) $3.0 \%$ drift (d) $4.0 \%$ drift (e) $5.0 \%$ drift (Beam is in positive bending i.e. top flange in compression)


\section{Experiment 0 Simulation -}

Fig. 5. Progression of HBS 5 beam cross-section buckling at interstory drifts, (a) 3\%, (b) 4\%, and (c) $5 \%$. Cross-section is located $406 \mathrm{~mm}$ from the column face, the beam is in positive bending and FE simulation predictions are plotted against recorded data from test.

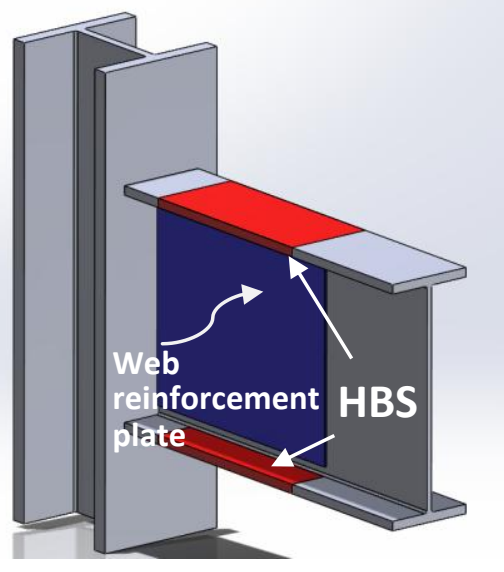

(a)

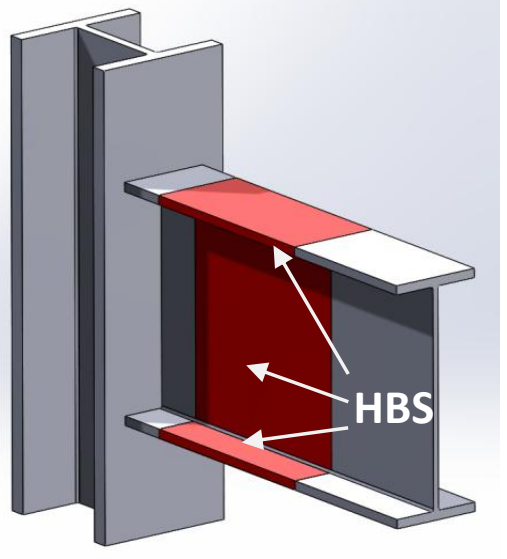

(b) 
Fig. 6. Proposed enhanced connections (a) HBS with web reinforcement plate (HBS-WR) (b) HBS applied to beam flanges and beam web (HBS-W)
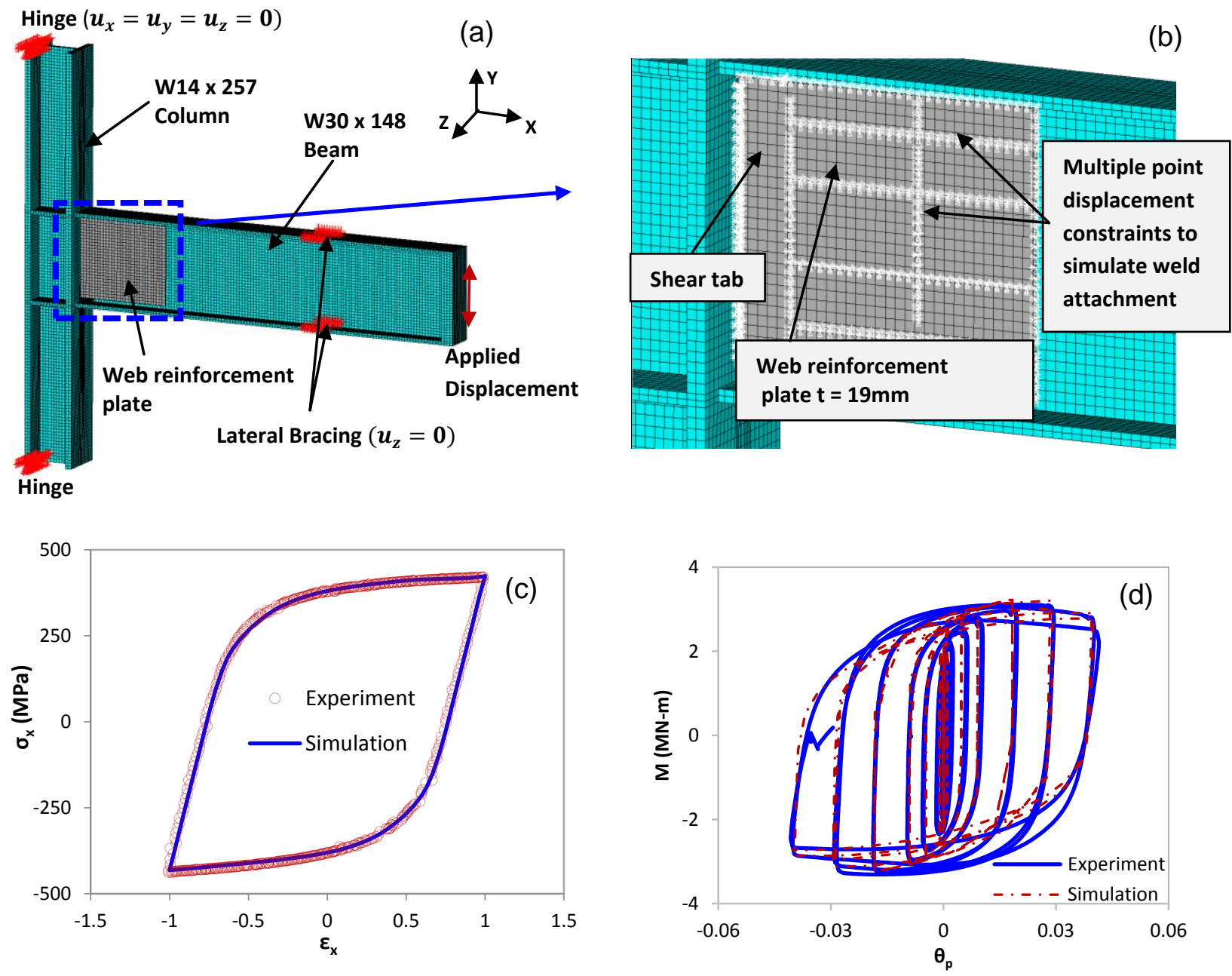

Fig. 7. (a) FE mesh and boundary coditions of HBS-WR (b) Close up view of mesh showing multi-point displacement constraints used to simulate welding attachment of the web reinforcement plate to beam web (c) fitted ASTM A992 hystersis curve (d) comparison of experiment and simulated moment-plastic rotation responses of HBS 5 


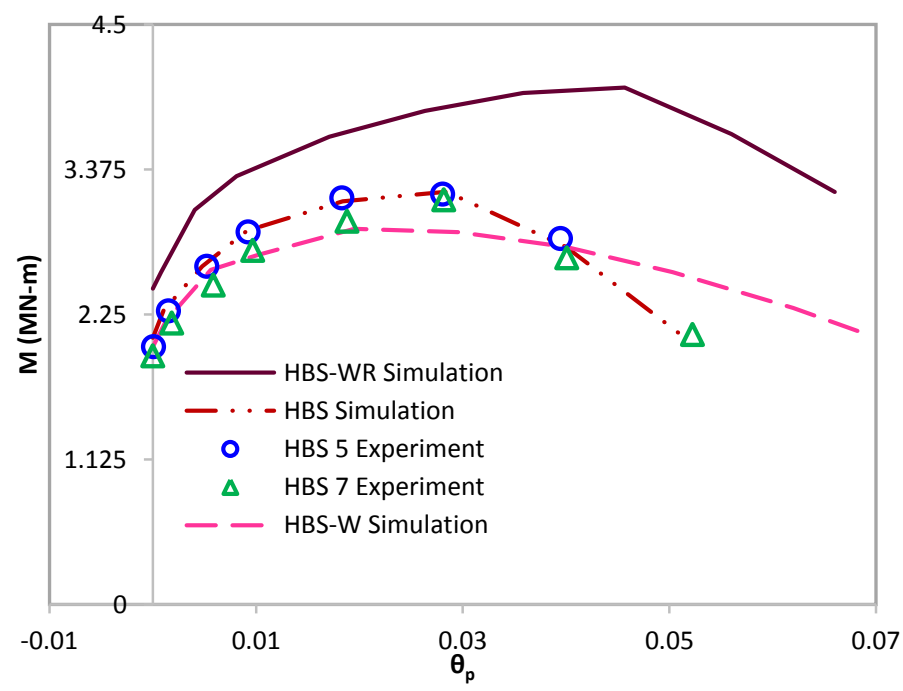

Fig. 8. Moment-plastic rotation backbone curves for HBS connections (experiment and simulation)
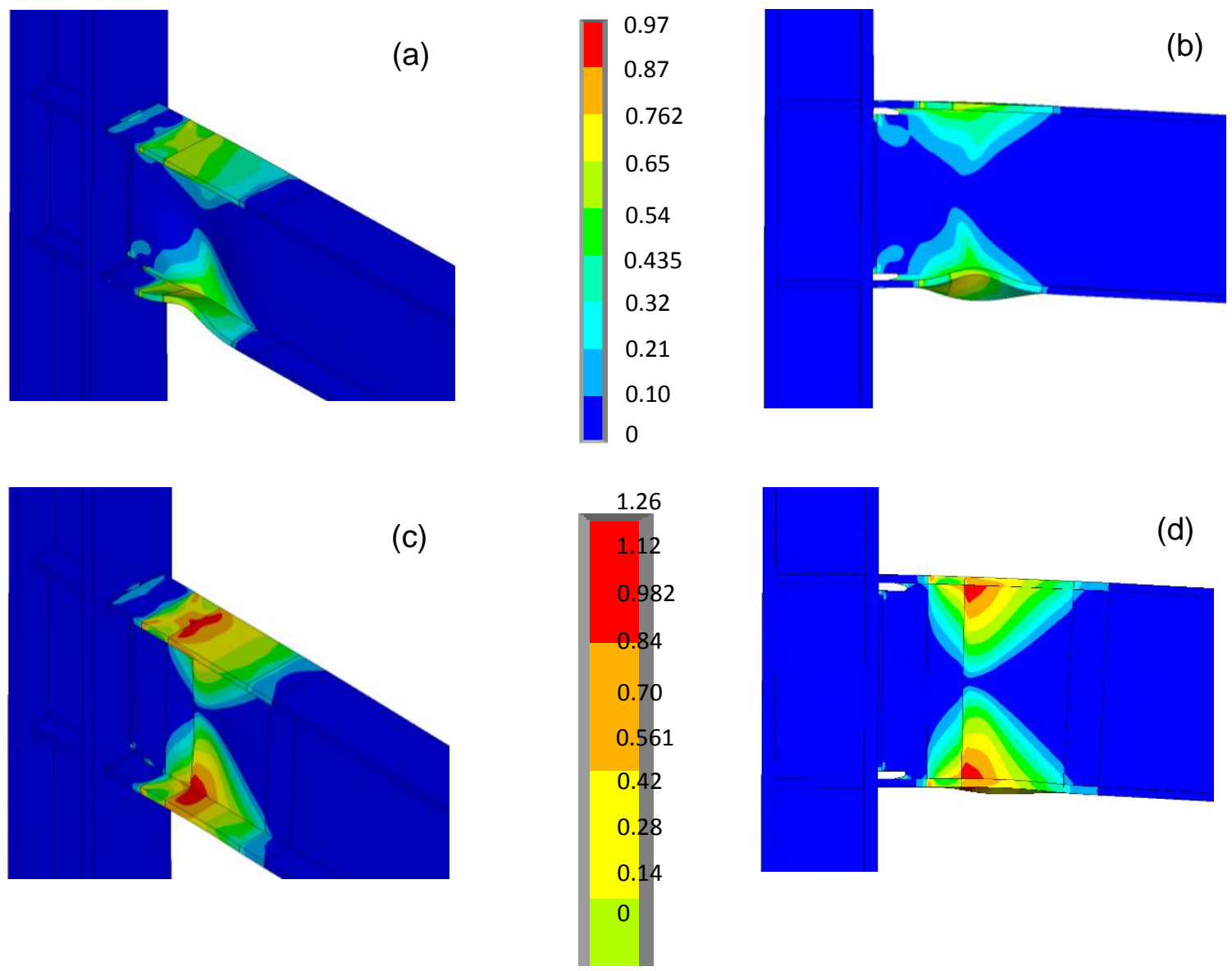

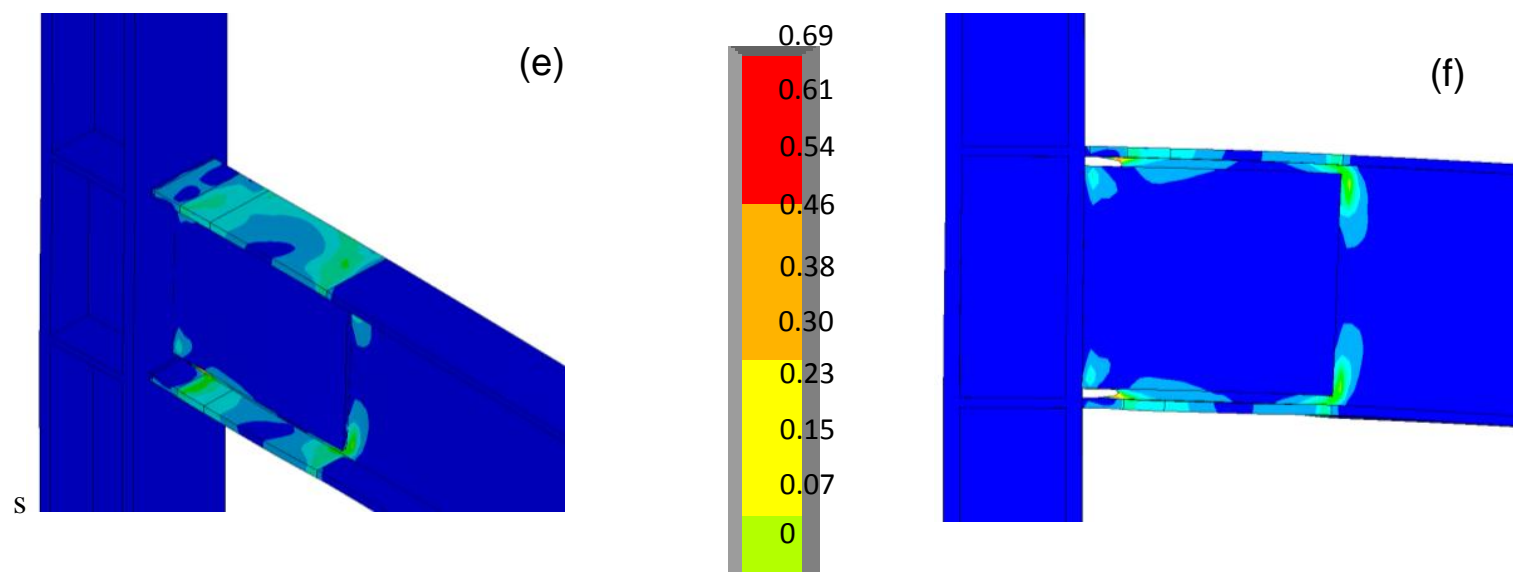

Fig. 9. Equivalent Plastic strain contours at 5\% story drift for moment connecitons (a) HBS (isometric) (b) HBS (elevation) (c) HBS-W (isometric) (d) HBS-W (elevation) (e) HBS-WR (isometric) (f) HBS-WR (elevation)


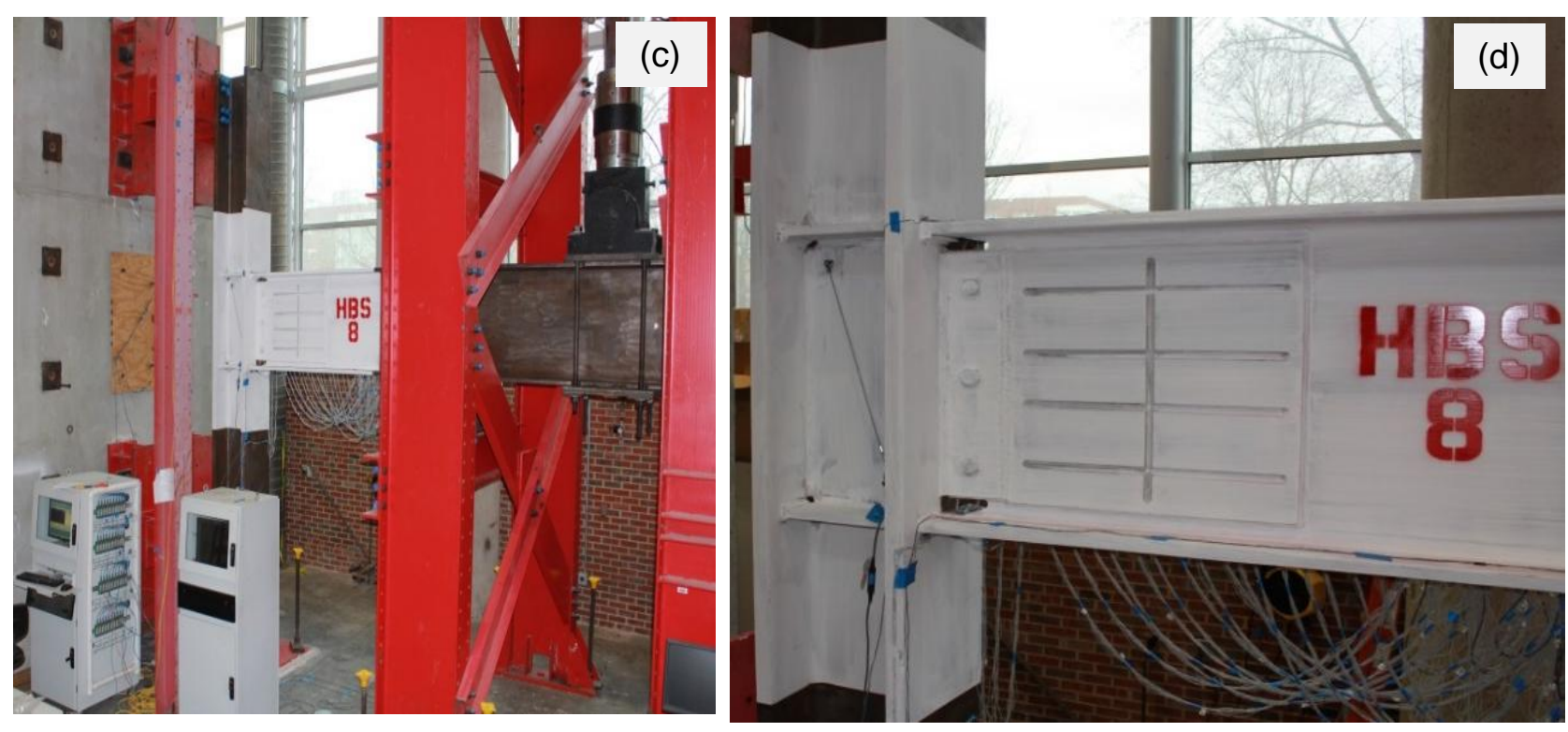

Fig. 10. HBS 8 test setup and connection details a) sketch of the test setup, b) sketch of the connection details, c) photograph showing test setup and, d) photograph of HBS 8 connection prior to testing


Fig. 11. Heat-treatment setup (a) photograph showing electric surface heating pads during installation on a beam flange[20], (b) photograph showing insulation of beam flange for well controlled heating and cooling[20] 

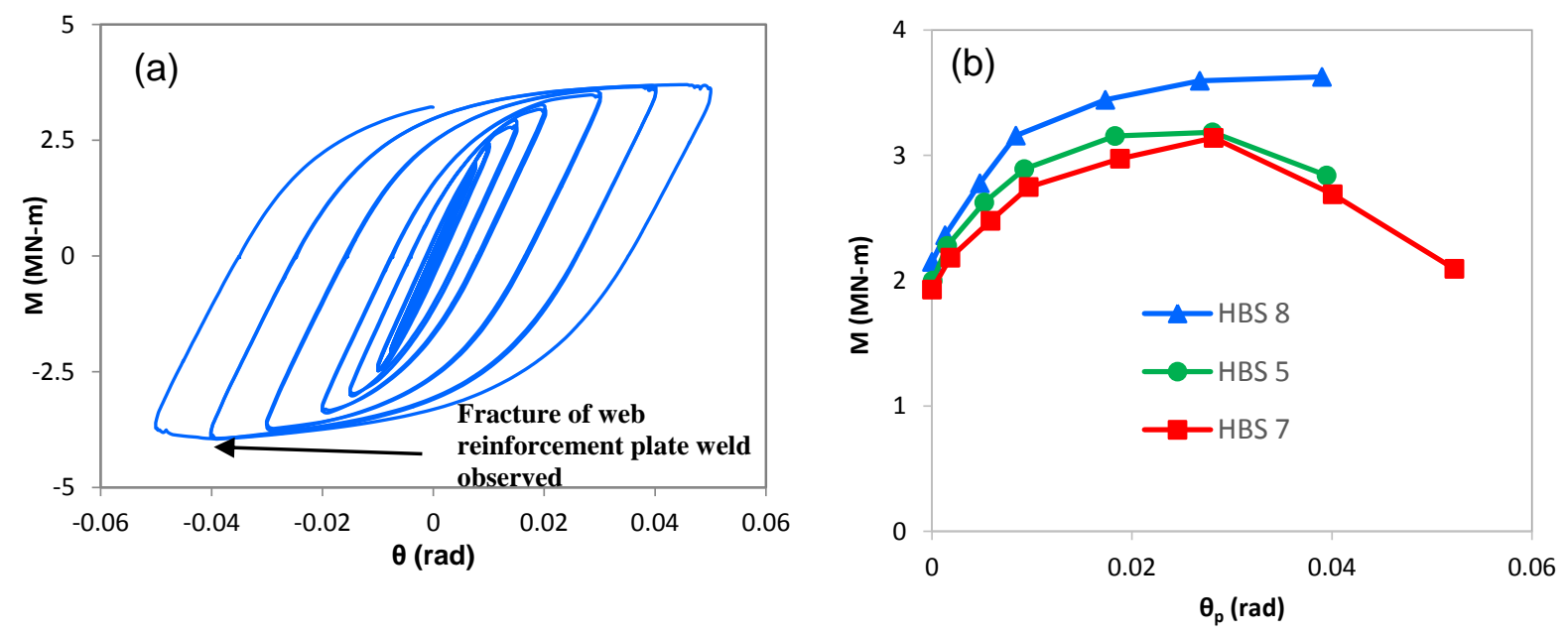

Fig. 12 (a) Moment-rotation response of HBS 8 (b) Moment-plastic rotation backbone curves for HBS 5, HBS 7 and HBS 8
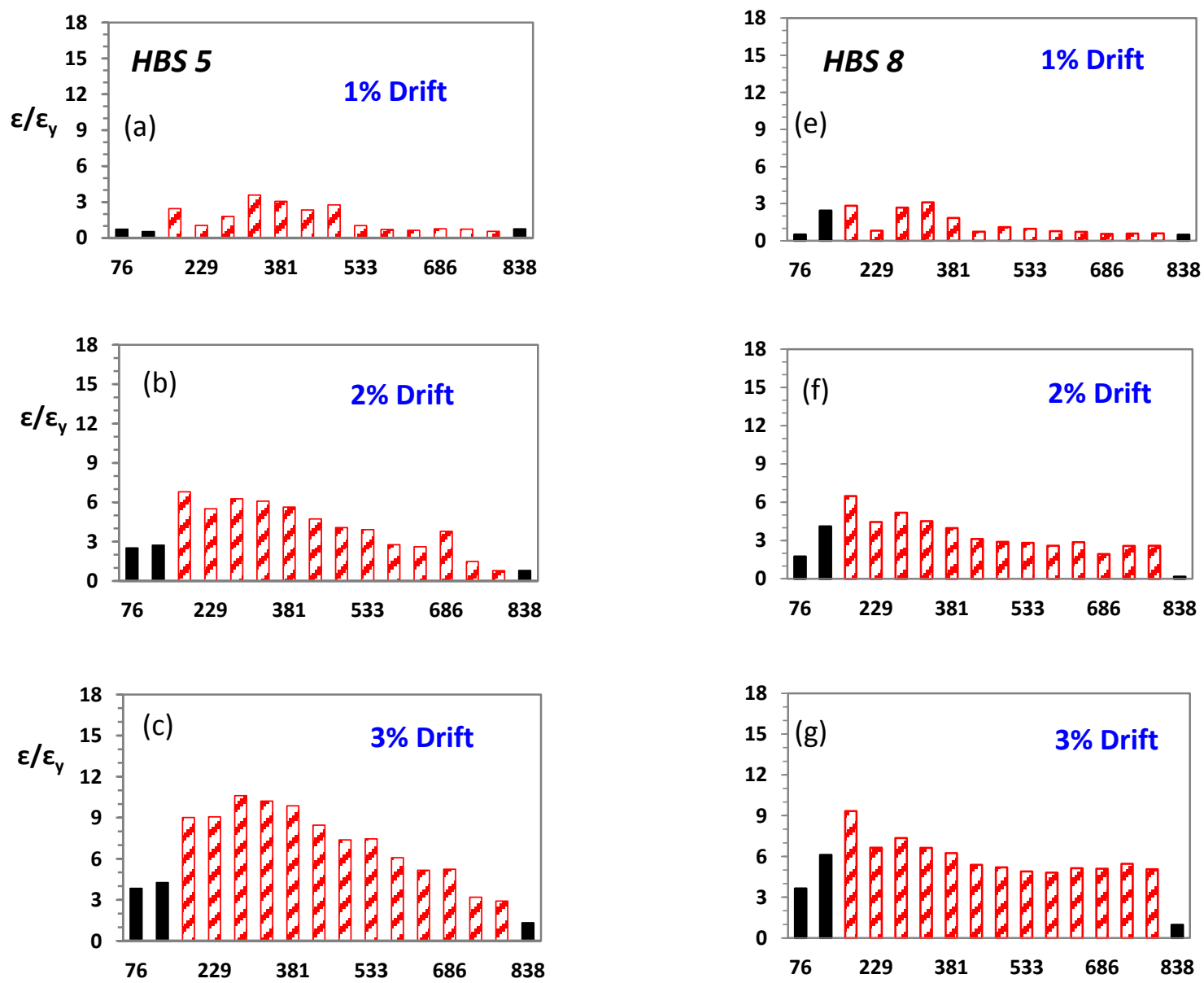

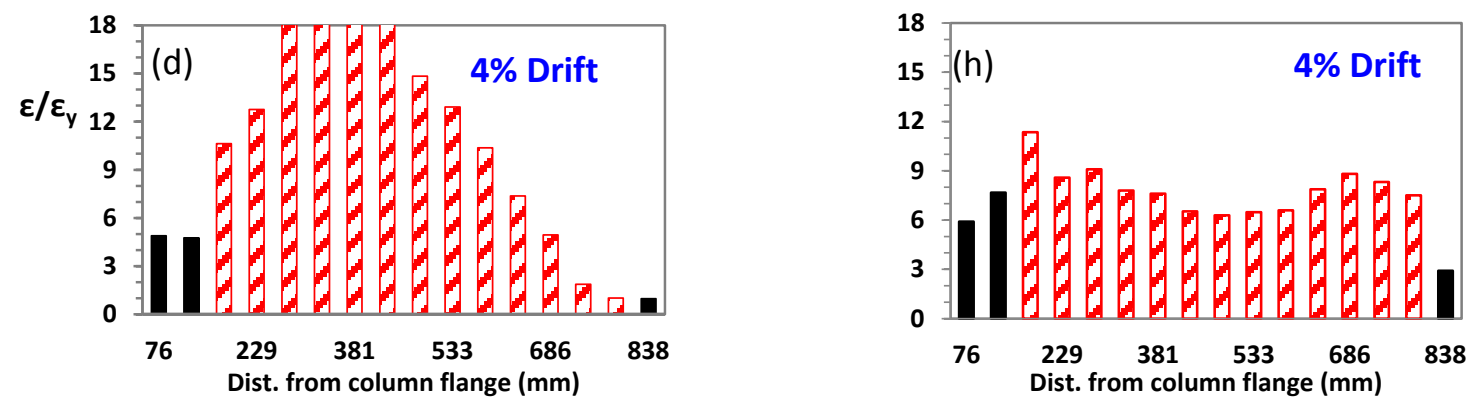

Heat-treated

Not heat-treated

Fig. 13. Recorded longitudinal strains along the center of top flange of the beam (a-d) HBS 5 and (e-h) HBS 8
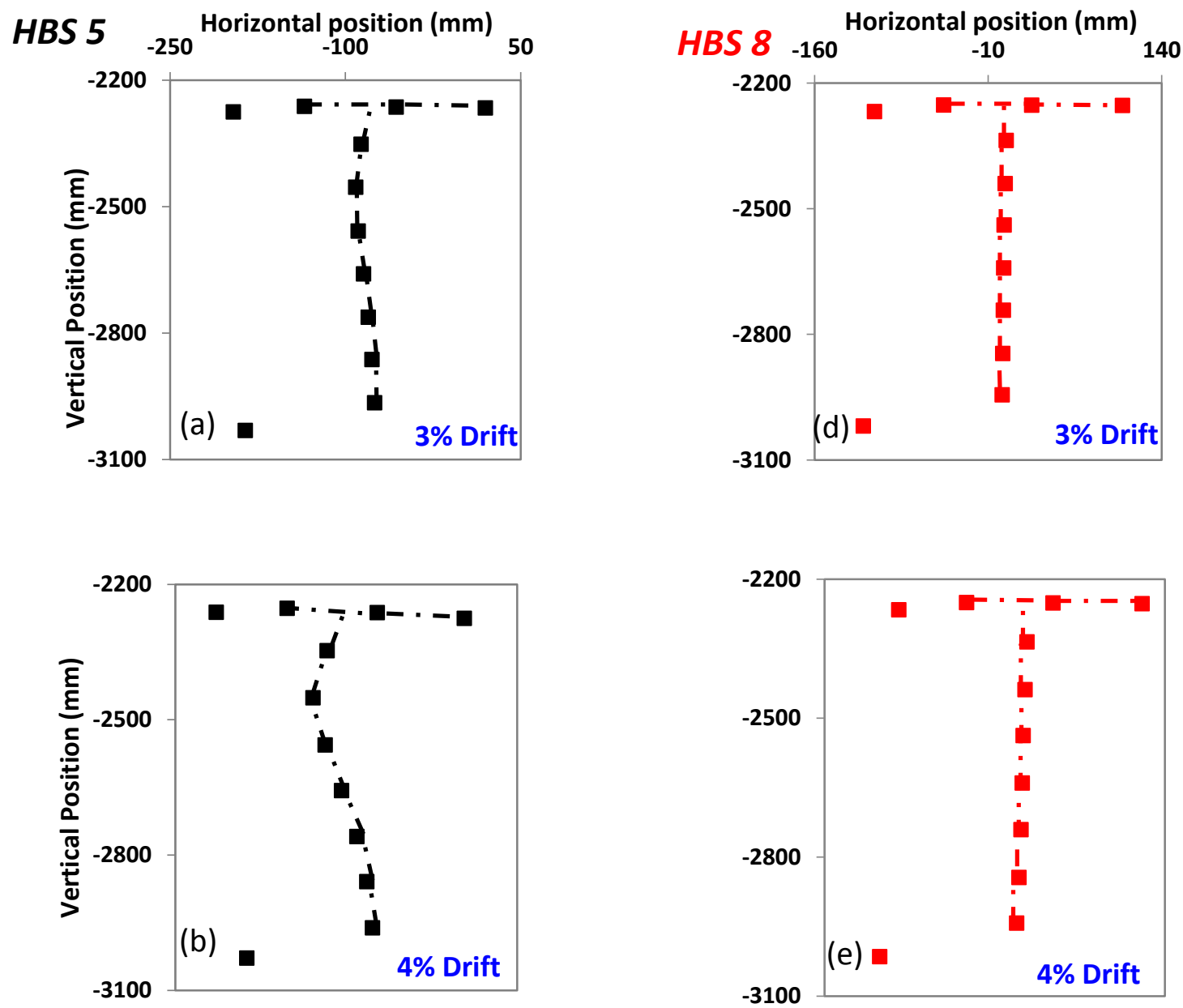

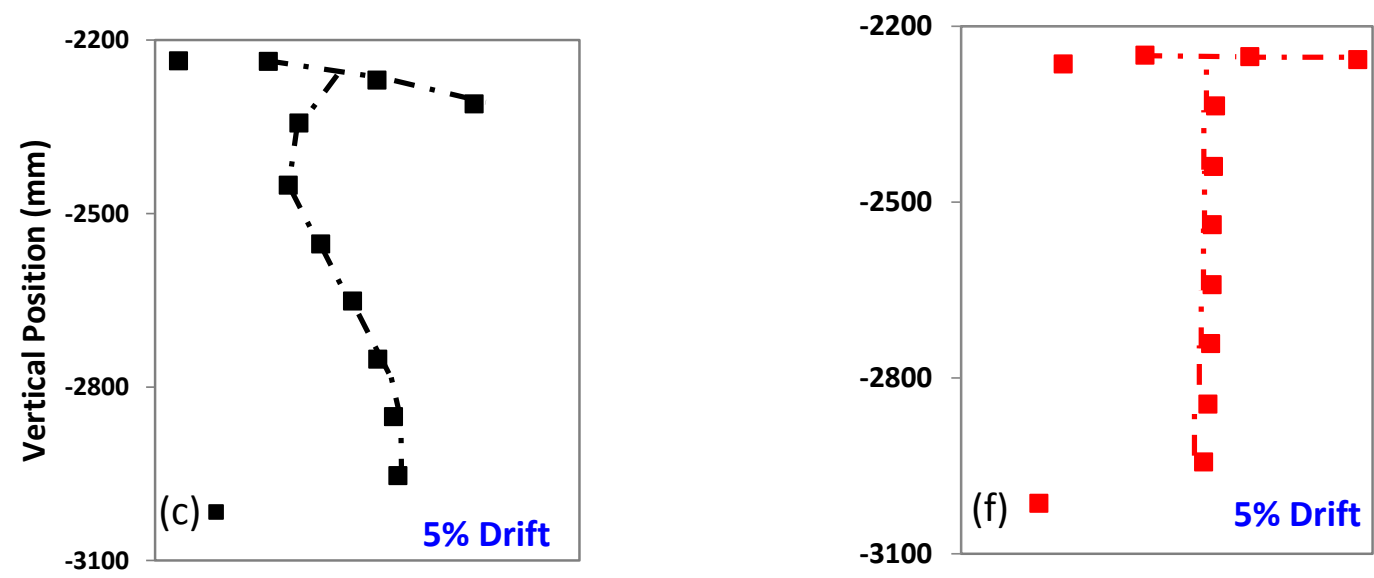

Fig. 14. Progression of beam web and flange buckling recorded $406 \mathrm{~mm}$ away from the column flange (a-c) HBS 5 and (d-f) HBS 8 (Beams are in positive bending i.e. top flange in compression).
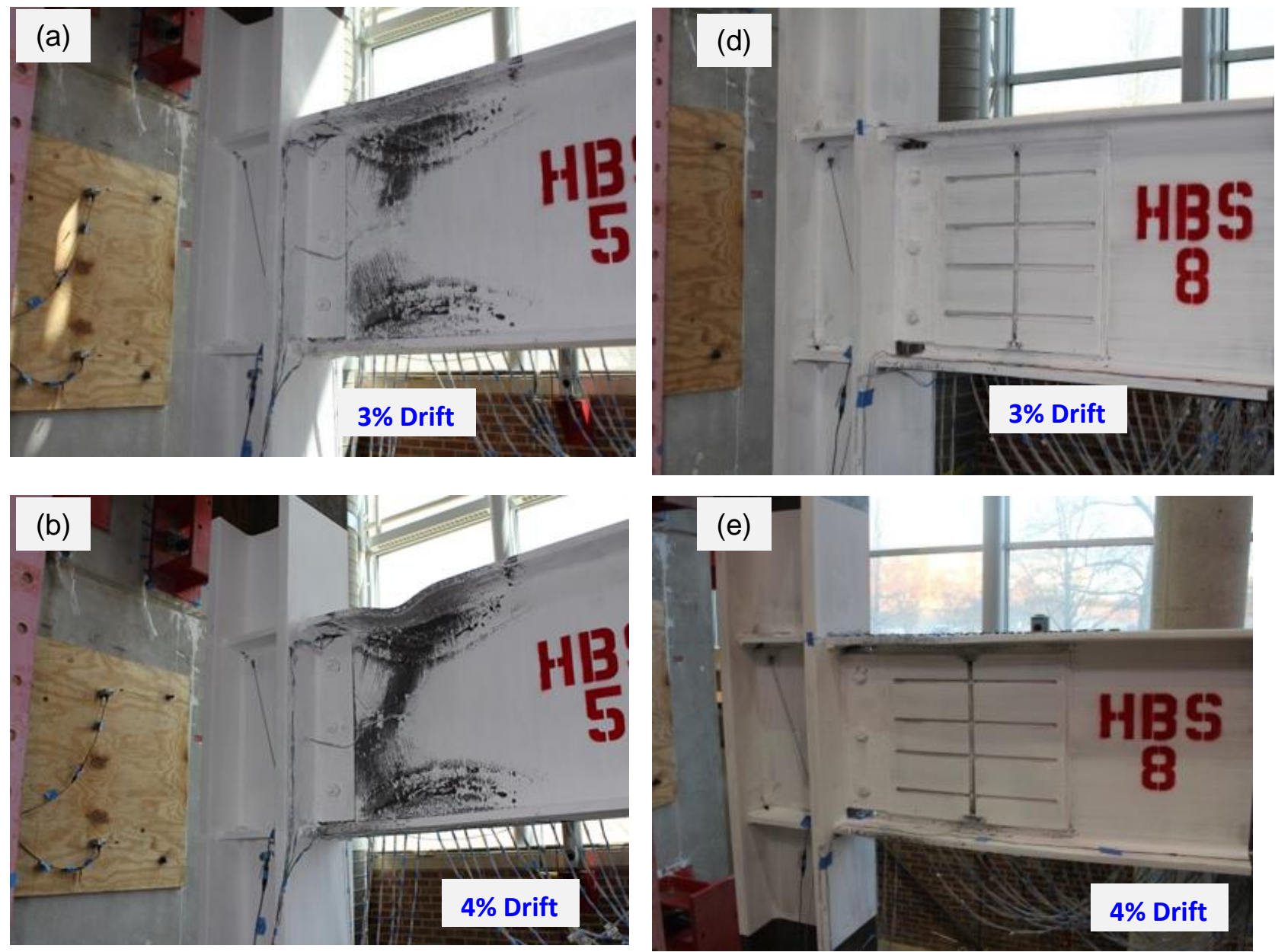

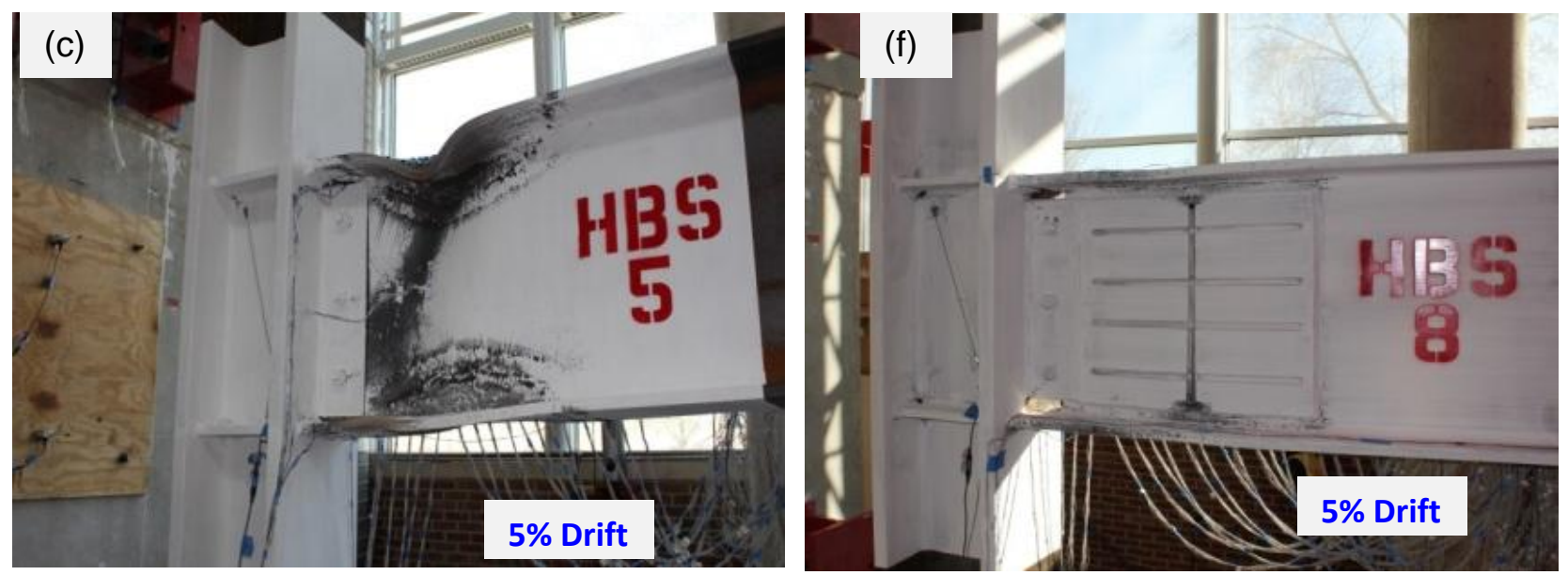

Fig. 15. Photographs comparing the yielding, plastic hinging and local buckling at various stages of the loading history for (a-c) HBS 5 and (d-f) HBS8

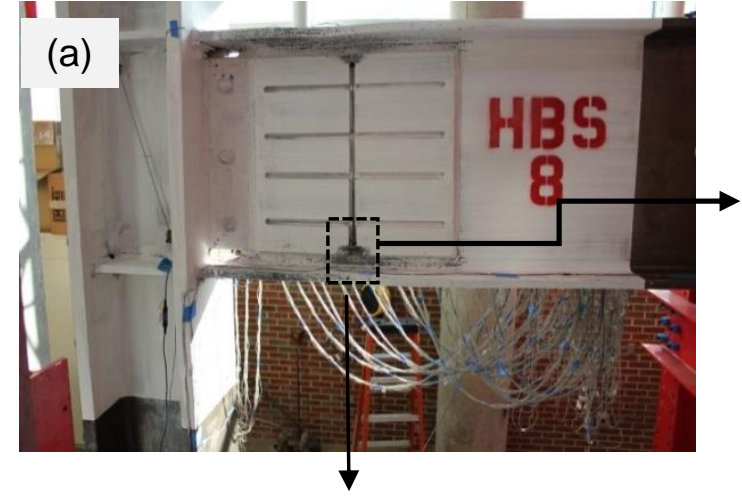

(c)

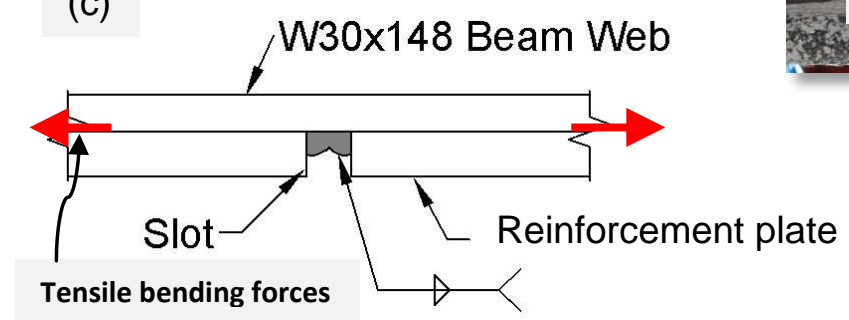

Fig. 16 (a) Posttest photograph showing fracture of web reinforcement fillet weld and beam web (b) enlarged photograph at the fracture location (c) Sketch of web reinforcement slot fillet weld detail

(b)



\section{te}


Table 1 Plastic rotation capacity and strength degradation ratios of HBS WSMCs

\begin{tabular}{|l|l|r|}
\hline Connection $^{1}$ & $\begin{array}{l}\boldsymbol{\theta}_{\mathbf{p c}} \\
\text { (radians) }\end{array}$ & $\begin{array}{r}\text { SDA(80 } \\
661 \\
662\end{array}$ \\
\hline HBS 5 & 0.039 & $\begin{array}{r}0.9663 \\
664\end{array}$ \\
\hline HBS 7 & 0.041 & $\begin{array}{r}0.888 \\
665\end{array}$ \\
\hline HBS-WR & 0.061 & $\begin{array}{r}0.9666 \\
667\end{array}$ \\
\hline HBS-W & 0.056 & $\begin{array}{r}0.9668 \\
669\end{array}$ \\
\hline
\end{tabular}

670 671

672

673

674

675

676

677

678

679

680

681

682

683

684

685

686

687

688

689

690

691

692

693

${ }^{1}$ All connections have the same beam (W30x148 beam) and column (W14x148) cross-sections.

\section{$\underline{\text { List of Figures }}$}

Fig. 1. (a) Measured local buckling modes and strength degradation of a RBS beam to column moment connection (Data from Yu et. al [9]) (b) Definition of plastic rotation capacity by Uang and Fan [10] (c) Definition of strength degradation ratio by Uang and Fan [10] (d) Limiting Slenderness Surfaces for RBS beam to column moment connections ( $F_{y}=345 \mathrm{MPa}$ ) [10] (e) Limiting Slenderness Surfaces for RBS beam to column moment connections $\left(F_{y}=223 \mathrm{MPa}\right)$ [10].

Fig. 2. (a) Sketch of heat-treated beam section (HBS) connection [20] (b) engineering stressstrain response of A992 and heat-treated A992 steel [20]

Fig. 3. Test results of HBS 5 and HBS 7 WSMCs, (a) HBS 5 moment-rotation response [20] (b) HBS 7 moment-rotation response [20] (c) photograph showing HBS 5 beam flange buckling and fracture at the crest of flange buckle (d) photograph showing plastic hinge formation and significant beam flange buckling of HBS 7.

Fig. 4. Progression of buckling in beam web of HBS 5 at various stages of loading history (a) initial position (b) $2.0 \%$ drift (c) $3.0 \%$ drift (d) $4.0 \%$ drift (e) $5.0 \%$ drift (Beam is in positive bending i.e. top flange in compression)

Fig. 5. Progression of HBS 5 beam cross-section buckling at interstory drifts, (a) 3\%, (b) 4\%, and (c) $5 \%$. Cross-section is located $406 \mathrm{~mm}$ from the column face, the beam is in positive bending and FE simulation predictions are plotted against recorded data from test

Fig. 6. Proposed enhanced connections (a) HBS with web reinforcement plate (HBS-WR) (b) HBS applied to beam flanges and beam web (HBS-W) 
694 Fig. 7. (a) FE mesh and boundary coditions of HBS-WR (b) Close up view of mesh showing multi-point displacement constraints used to simulate welding attachment of the web reinforcement plate to beam web (c) fitted ASTM A992 hystersis curve (d) comparison of experiment and simulated moment-plastic rotation responses of HBS 5

Fig. 8. Moment-plastic rotation backbone curves for HBS connections (experiment and simulation)

Fig. 9. Equivalent Plastic strain contours at 5\% story drift for moment connecitons (a) HBS (isometric) (b) HBS (elevation) (c) HBS-W (isometric) (d) HBS-W (elevation) (e) HBS-WR (isometric) (f) HBS-WR (elevation)

Fig. 10. HBS 8 test setup and connection details a) sketch of the test setup, b) sketch of the connection details, c) photograph showing test setup and, d) photograph of HBS 8 connection prior to testing

Fig. 11. Heat-treatment setup (a) photograph showing electric surface heating pads during installation on a beam flange [20], (b) photograph showing insulation of beam flange for well controlled heating and cooling [20]

Fig. 12 (a) Moment-rotation response of HBS 8 (b) Moment-plastic rotation backbone curves for HBS 5, HBS 7 and HBS 8

Fig. 13. Recorded longitudinal strains along the center of top flange of the beam (a-d) HBS 5 and (e-h) HBS 8

Fig. 14. Progression of beam web and flange buckling recorded $406 \mathrm{~mm}$ away from the column flange (a-c) HBS 5 and (d-f) HBS 8 (Beams are in positive bending i.e. top flange in compression)

Fig. 15. Photographs comparing the yielding, plastic hinging and local buckling at various stages of the loading history for (a-c) HBS 5 and (d-f) HBS8

Fig. 16 (a) Posttest photograph showing fracture of web reinforcement fillet weld and beam web (b) enlarged photograph at the fracture location (c) Sketch of web reinforcement slot fillet weld detail

\section{$\underline{\text { List of Tables }}$}

Table 1 Plastic rotation capacity and strength degradation ratios of HBS WSMCs 